\title{
Adult children of alcoholics' perceptions of communicative exchanges with family members and outsiders
}

\author{
Kerry Byrnes \\ West Virginia University
}

Follow this and additional works at: https://researchrepository.wvu.edu/etd

\section{Recommended Citation}

Byrnes, Kerry, "Adult children of alcoholics' perceptions of communicative exchanges with family members and outsiders" (2010). Graduate Theses, Dissertations, and Problem Reports. 4567.

https://researchrepository.wvu.edu/etd/4567

This Dissertation is protected by copyright and/or related rights. It has been brought to you by the The Research Repository @ WVU with permission from the rights-holder(s). You are free to use this Dissertation in any way that is permitted by the copyright and related rights legislation that applies to your use. For other uses you must obtain permission from the rights-holder(s) directly, unless additional rights are indicated by a Creative Commons license in the record and/ or on the work itself. This Dissertation has been accepted for inclusion in WVU Graduate Theses, Dissertations, and Problem Reports collection by an authorized administrator of The Research Repository @ WVU.

For more information, please contact researchrepository@mail.wvu.edu. 
Adult Children of Alcoholics' Perceptions of Communicative Exchanges with Family Members and Outsiders

\title{
Kerry Byrnes
}

Dissertation submitted to the The Eberly College of Arts and Sciences at West Virginia University in partial fulfillment of the requirements for the degree of

\section{Doctor of Philosophy in Communication Studies}

\author{
Maria Brann, Ph.D., Chair \\ Matthew M. Martin, Ph.D. \\ Scott A. Myers, Ph.D. \\ Keith Weber, Ed.D. \\ William Reger-Nash, Ph.D. \\ Department of Communication Studies
}

\author{
Morgantown, West Virginia \\ 2010
}

Keywords: Alcoholism, Family, Communication Privacy Management Theory 


\begin{abstract}
Adult Children of Alcoholics' Perceptions of Communicative Exchanges with Family Members and Outsiders
\end{abstract}

Kerry Byrnes

Millions of children grow up in alcoholic homes. For these children, their lives are changed forever. As a result of being socialized in a home in which at least one parent is an alcoholic, the children suffer with a number of negative consequences. Children of alcoholics (COAs) have cognitive difficulty and often do not excel in scholastic endeavors. It is also difficult for COAs to form lasting relationships with others outside the family. Because they are often socialized in a home in which secrecy is advocated, creating relationships and fully disclosing about experiences proves to be challenging. As a result, COAs often experience lowered levels of relationship trust and satisfaction. Thus, COAs have difficulties forming meaningful relationships in which they can disclose about their experiences and do not, as a consequence, experience the benefits of social support. The present study used a Communication Privacy Management (CPM) Theory framework to understand how COAs control access to their private information. I examined COAs' relationships, what information they reveal, why they reveal the information they do, and to whom information is then revealed. Using qualitative data collection methods, I conducted 20 interviews with COAs who had an alcoholic father or stepfather. Interviews lasted approximately 90 minutes. All interviews were guided by questions grounded in CPM. CPM maintains that individuals own private information. As a result of this ownership, individuals make careful decisions about how to give others access to the information. Private information can thus be thought of as a commodity with individuals granting access. Results of the interviews indicated that COAs (a) developed privacy rules for access based on motivation and context, (b) were socialized in homes in which secrecy is advocated, (c) experienced trigger events that alter their privacy rules, (d) shared information with family and non-family members, (e) told others a set of standby stories, (f) did not have explicit discussions with confidants about what can be done with the information, and $g$ ) did not experience boundary turbulence as a result of sharing. Overall, COAs carefully considered the types of information they revealed to individuals. 


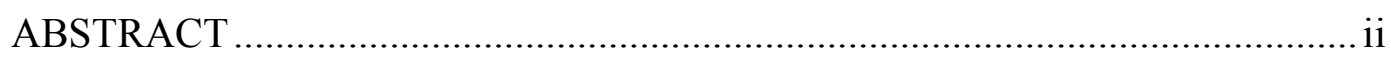

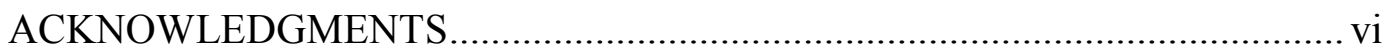

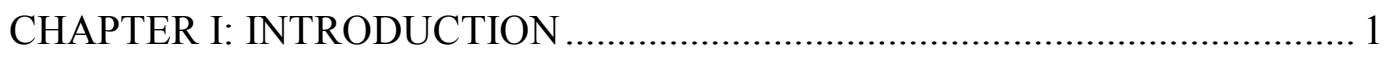

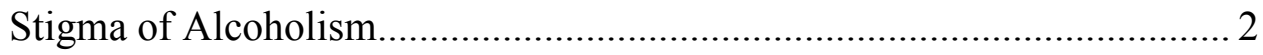

Defining Alcoholism ......................................................................... 3

Understanding the Alcoholic...................................................................... 4

The Impact of Alcoholism on Others' Health..............................7

The Family System.................................................. 8

Adjusting to the Alcoholic ......................................................... 9

The Family Climate.................................................................... 12

Types of Alcoholic Families ......................................................... 13

Children in the Alcoholic Family ............................................................ 14

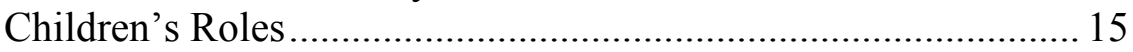

Outcomes Associated with Being a COA ……………................ 16

Relationships Outside the Family …………………….......................... 19

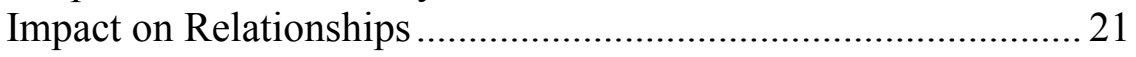

Communication Privacy Management Theory ………………………...... 23

Boundary Structures ................................................................ 24

Rule Management Processes........................................................ 26

Privacy Rule Foundations ................................................. 26

Boundary Coordination Operations ................................... 29

Boundary Turbulence .................................................... 33

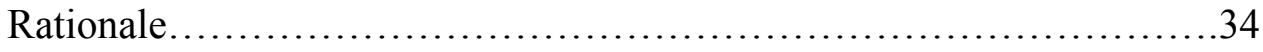

Research Question 1......................................36

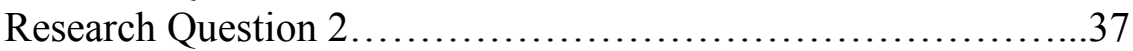

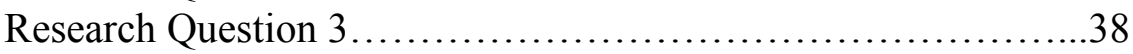

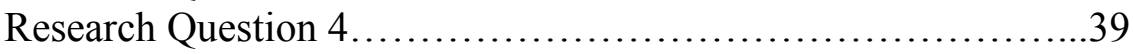

Research Question 5 .......................................40

Research Question 6......................................41

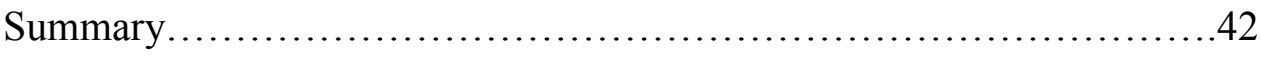

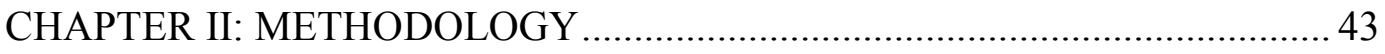

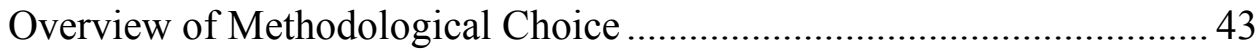

Sampling and Recruitment Procedures ................................................... 45

Participants and Procedures .................................................................... 47

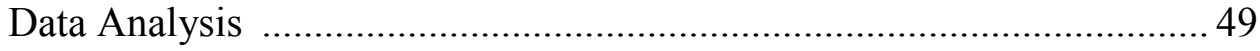

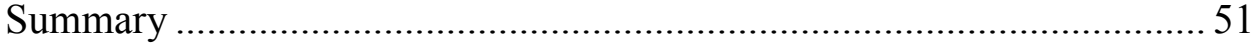


CHAPTER III: RESULTS............................................... 52

Factors Impacting Disclosure Decisions............................ 53

Management Process One: Rule Foundations........................ 54

Research Question One Results............................55

Research Question Two Results..............................58

Management Process Two: Boundary Coordination Operations.........66 61

Research Question Three Results............................ 61

Research Question Four Results............................. 64

Research Question Five Results............................67

Management Process Three: Boundary Turbulence.....................69 69

Research Question Six Results............................69

Summary................................................. 71

CHAPTER IV: DISCUSSION ........................................... 72

Theoretical Implications........................................ 74

Practical Implications.............................................. 76

Limitations.................................................... 78

Directions for Future Research................................... 80

Conclusion...................................................... 82

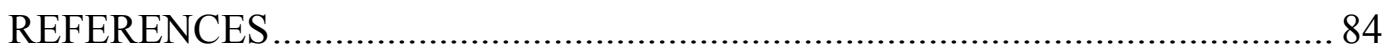

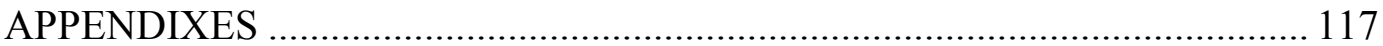

Appendix A: Handout Given at Al-Anon Meetings............................ 117

Appendix B: Facebook Status.......................................... 118

Appendix C: Logistics Information for Interviewees..................119

Appendix D: Interview Guide............................... 120

Appendix E: Code Book......................................124 


\section{List of Figures}

$\underline{\text { Page }}$

Figure 1. Rule Management Process 1: Privacy Rule Foundations ..................... 27

Figure 2. Rule Management Process 2: Boundary Coordination Operations ....... 30

Figure 3. Rule Management Process3: Boundary Turbulence....................33 


\section{Acknowledgements}

I need to thank several people for helping me complete this project including my advisor, committee, and parents. First, I first need to thank my advisor, Dr. Maria Brann, for being willing to address such a sensitive topic. This project was made significantly better by her questions and thoughtful feedback; it is because of her support that this project was completed. Second, my committee also deserves credit for constantly asking me to think carefully about my method, arguments, and findings. This project was greatly enhanced by their critique and is stronger as a result. Finally, I need to thank my parents. Without them, I would not have realized my dreams. Their unwavering love and support only reinforced the fact that I could do anything I wanted. For believing in me when I could not believe in myself, I am eternally indebted to all who helped me achieve this goal. 


\section{Chapter 1}

\section{Introduction}

While an extensive body of research outlines the impact alcohol makes on every aspect of the body (see, for example, Anderson, Wallace, \& Jones, 1988; Lieber, 1977), an increasingly large body of knowledge has uncovered how alcoholism impacts the alcoholic and his/her interactions with both family and non-family individuals. Researchers are able to answer a number of questions including things such as an alcoholic's personality characteristics and the processes and behaviors that occur among the members of the alcoholic home. Increasing research on alcoholism is well deserved as a large number of adults and children are a part of an alcoholic home. While the exact number is difficult to determine, it is estimated that 17.6 million adults in the United States, or about 1 in every 12 adults, with a majority of these people being men (National Institute on Alcohol Abuse and Alcoholism [NIAAA], 2007), are alcoholics.

Additionally, an estimated 53\% of adults in the United States reported that one or more of their relatives has a drinking problem (Alcoholics Info, n. d.), and an estimated 28 million children, or roughly one in seven, live in an alcoholic home (Grant, 2000).

Answering a call issued by Grant (2000) that indicated more research is needed to examine how children of alcoholics cope and manage their exposure to alcoholism, the present study examined how children of alcoholics (COAs) share information with others. The act of sharing information with others is best conceptualized by the self disclosure literature. To self disclose, an individual verbally shares information about oneself to another person (Derlega \& Chaikin, 1977). While the health benefits associated with revealing information and sharing secrets with others is plentiful (see, for 
example, Pennebaker, Zech, \& Rimé, 2001), individuals still choose to remain silent and conceal secrets from others close to them (e.g., Afifi, Olson, \& Armstrong, 2005; Afifi \& Steuber, 2008). These individuals may perceive concealing private information to be beneficial if they anticipate negative consequences once the information is shared with

others. Information may be selectively shared because of fear of negative evaluation (Black \& Miles, 2002), rejection from others (Cline \& McKenzie, 2000), or self protection (Afifi \& Guerrero, 2000). However, when disclosive attempts are made, individuals experience increased physical health (Greenberg \& Stone, 1992), self-esteem (Afifi \& Caughlin, 2006), and insights about information (Kelly, Klusas, von Weiss, \& Kenny, 2001). Thus, it appears that individuals need to weigh the costs and benefits of disclosing private information with others as it can have both positive and negative effects.

For families dealing with alcohol addiction, the need to manage information is arguably increased. Disclosing information about the alcoholic can be especially difficult because of the social stigma attached to alcoholism (Brady, Tolliver, \& Verduin, 2007). The purpose of this study is to investigate how children from alcoholic families communicate information about their alcoholic home with others, both inside and outside the family unit.

\section{Stigma of Alcoholism}

Stigma is considered a negative social phenomenon. Individuals are stigmatized when they possess a characteristic or behavior that is undesirable and as a result does not meet standards of society (Crocker \& Major, 1989). While treatment programs encourage and promote feelings of dignity (Stigma associated with alcohol dependence 
treatment, 2009), it is difficult for individuals to reach out and indicate a need for help because of negative societal perceptions of those with an addiction. When an individual identifies as an alcoholic, the reaction can be negative. Cash, Briddell, Gillen, and MacKinnon (1984) found individuals who were labeled as excessive drinkers were perceived as deviant, not in control, and psychologically ineffective, and as a result, rejected as a potential friend. However, not all individuals who consume alcohol are considered to be alcoholics. The literature has attempted to define alcoholism and separate it from social drinking behaviors.

\section{Defining Alcoholism}

Historically, defining alcoholism, also described as alcohol dependence, has proven to be difficult. Common to most definitions of alcoholism is an idea of drinking more than what is "normal." If normal drinking behaviors mean drinking less than what is required to produce psychological, medical, or social problems, alcoholism is repeatedly exceeding those limits (Manzardo, Goodwin, Campbell, Penick, \& Gabrielli, 2008). Alcoholism also has been conceptualized as a disease, as a symptom of other diseases, a vice, a sin, a choice, or something that if used makes an individual an alcoholic (Jellinek, 1960; Keller, 1958; McCord \& McCord, 1960). However, among these differing thoughts, there is one definition that is relatively widely adopted. Keller (1958) described alcoholism as "being a behavioral disorder manifested by repeated drinking of alcoholic beverages in excess of the dietary and social uses of the community and to an extent that interferes with the drinker's health or his [sic] social or economic functioning" (p. 2). While this definition does not clarify whether alcoholism is a disease, 
an issue that was once debated (Todd, 1882), it does suggest that one who is addicted to alcohol is indeed an alcoholic.

An alcoholic also can be thought of in terms of the social drinker gone awry; the alcoholic begins by drinking in the company of others as a social tool and becomes an individual preoccupied by alcohol (Jellinek, 1952). Much more recent definitions have characterized alcoholism using four traits: cravings, loss of control, physical dependence, and tolerance (Abrams et al., 1991; NIAAA, 2007). These traits include cravings or a strong need or urge for alcohol. An alcoholic will experience the urge to drink regardless of the situation (Abrams et al., 1991). Loss of control refers to feelings so intense that once the alcoholic begins to drink, he/she cannot stop. This loss of control and inability to stop contributes to a physical dependence, the third characteristic. Physical dependence refers to withdrawal symptoms that would occur if the alcoholic stopped drinking. These include symptoms such as nausea, vomiting, and headaches would occur. The final characteristic is tolerance. The tolerance of the alcoholic is high and great amounts of alcohol are needed in order to feel "high" (NIAAA, 2007).

\section{Understanding the Alcoholic}

Researchers not only have attempted to define alcoholism, but they also have begun to uncover some reasons alcoholics engage in excessive drinking. Alcoholics admittedly drink for a number of reasons including the need to feel relief from life, reduce stress, reward themselves (Ooteman, Koeter, Verheul, Schippers, \& Van den Brink, 2006; Verheul, Van den Brink, \& Geerlings, 1999), relax or make friends (Olenick \& Chalmers, 1991), or become intoxicated or reduce depression (McMahon, Kouzekanai, DeMarco, Kusel, \& Davidson, 1992). Alcohol can be used as a coping mechanism (i.e., a 
way to deal with life's problems), which indicates an increase in mental and behavioral disengagement, suppression of activities, and denial of problems (Britton, 2004).

These drinking motives contribute to a number of negative behavioral displays. The alcoholic acts in narcissistic ways and does not address the needs of others (Cornwell, 1968) nor is the alcoholic affectionate with others (McCord \& McCord, 1960). This person will avoid responsibility in every facet of life (Finlay, 1974) and is aloof (Weiner, Tamerin, Steinglass, \& Mendelson, 1971) and antisocial (Jacob, Leonard, \& Haber, 2001). Ultimately, the research on motives for drinking and subsequent behavioral displays suggests that alcoholics drink for a number of reasons, and the result of these drinking patterns can be behavioral displays that can affect those around the alcoholic.

Discovering the definition, motivations, and behavioral displays of drinking has contributed to the development of a typology of alcoholics. Jellinek (1960) outlined one of the first typologies of alcoholics. Using the Greek alphabet, Jellinek created four distinct types of alcoholics: Alpha, Beta, Gamma, and Delta alcoholics. The Alpha alcoholic, also labeled problem drinker, is the least severe of the types. In this type, an individual has a psychological dependence on alcohol to help relieve emotional or physical pain. There are relatively few side effects of the person's drinking patterns, and an occasional missed day of work or strain on the family's budget are the extent of the problems associated with this drinker (Jellinek, 1960). The Beta alcoholic emerges from a culture in which there is a poor diet and heavy drinking. Medical issues such as gastritis and cirrhosis surround this drinker. Gamma alcoholics are reliant on alcohol, have withdrawal symptoms, experience cravings, and have a loss of control. Noticeable 
behavior changes occur and interpersonal relationships can be severely damaged due the erratic nature of the alcoholic (Jellinek, 1960). This type of alcoholic is also the most common type in the United States. Gamma alcoholics are able to quit drinking, but this stop in drinking behaviors typically only lasts for short periods of time. In contrast, the Delta alcoholic cannot stop drinking for even a short period of time. This person continues drinking and has similar experiences to the Gamma alcoholic. This alcoholic also would not seek treatment for problems (Jellinek, 1960).

These alcoholic types have contributed to the development of a large body of literature that focuses on understanding the male alcoholic (Ackerman, 1986; Grant, 1998; Rubio-Stipec, Bird, Canino, Bravo, \& Alegria, 1991). Researchers have investigated the female alcoholic (Kubicka, Csémy, \& Kozený, 1992; Piazza, Vrbka, \& Yeager, 1989) and the elderly alcoholic (Adams \& Cox, 1995; Liberto \& Oslin, 1995). However, this literature is relatively scant in comparison to the research on male alcoholics as there are nearly three times as many male alcoholics as there are female alcoholics (Bailey, 1968; NIAAA, 1990). Moreover, female and male alcoholics are noticeably different. Women tend to develop alcoholism later in life than men (Winokur \& Clayton, 1968) and depend on alcohol to improve their lives more than male alcoholics (Haber \& Jacob, 1997). They also experience more depression and guilt for their drinking than male alcoholics (Tamerin, Tolor, \& Harrington, 1976). Because of these differences, the present research study limits its scope and focused solely on understanding the experiences of those raised in families with male alcoholics as they are more prevalent than female alcoholics. 
It appears that alcoholics are controlled by their need to drink, but not all alcoholics are alike nor do they all share the exact same experiences. However, there are some general conclusions that can be made about their reasons for drinking. It appears that alcoholics drink for a number of mostly selfish reasons. These motives and drinking patterns result in behaviors that are antisocial and impacts the alcoholic's ability to interact with others.

\section{The Impact of Alcoholism on Others' Health}

A variety of health outcomes are associated with being exposed to alcoholism. Generally, those individuals exposed to alcoholics are less happy with their lives (Callan \& Jackson, 1986). They are subjected to more stressors and, as a result, experience lowered mental health (Dawson, Brant, Chou, \& Stinson, 2007). More specifically, they experience heightened anxiety and psychoticism (Senchak, Greene, Carroll, \& Leonard, 1996; Steinglass, 1981), higher levels of neuroticism (Benson \& Heller, 1987;

Kashubeck, 1994), and have lower levels of well-being (Baker \& Stephenson, 1995). Perhaps the two most noteworthy outcomes associated with being surrounded by alcoholism is the increased likelihood to suffer from depression or have depressive symptoms (Domenico \& Windle, 1993; Hinkin \& Kahn, 1995; Jarmas \& Kazak, 1992; Rolf, Johnson, Israel, Baldwin, \& Chandra, 1988; Rubio-Stipec et al., 1991; Tweed \& Ryff, 1991) and the development of alcohol problems (Barnow, Schuckit, Lucht, John, \& Freyberger, 2002; Beseler, Aharonovich, Keyes, \& Hasin, 2008; Chassin \& Barrera, Jr., 1993; Chermack, Stoltenberg, Fuller, \& Blow, 2000; Curran \& Chassin, 1996; Díaz et al., 2008; Duncan et al., 2006; Sher, Walitzer, Wood, \& Brent, 1991; Weitzman \& Wechsler, 2000). Not only does the alcoholic impact the health of those in the family, but the 
alcoholic also disrupts the entire family system. In fact, for every one alcoholic, it is estimated that there are at least five or six people related to the alcoholic that are adversely affected by the person's drinking problem (Hecht, 1973) and as many as one in four children younger than 18 years old are exposed to alcoholism in the family (Grant, 2000).

\section{The Family System}

Families have been defined as transactional systems that impact one another (Hecht, 1973), and alcoholism is described as having centricity or the ability to affect all aspects of life within the family (Berlin, Davis, \& Orenstein, 1988). Alcoholism will create some impact on all members of a family and that impact is experienced by all in the family. Steinglass and his colleagues (Steinglass, 1971; Steinglass \& Moyer, 1977; Steinglass, Weiner, \& Mendelson, 1971) advocated for the development of research that focused on the family as a collective group rather than individuals in the family. They contended that researchers had compelling reasons to investigate how the individual effects of alcohol also impacted family and relational functioning. Steinglass (1980) further contended the family unit may be particularly situated to investigate how daily patterns of interaction are informed and influenced by the use of alcohol. He indicated that patterns of behavior in the family would become "flavored by the style and consequences of alcohol use" (p. 213). Thus, the family members' behaviors are influenced by the presence of alcoholism in the home. Moreover, studies (Cotton, 1979; Fitzgerald, Puttler, Refior, \& Zucker, 2007; Templer, 1974) indicated that the offspring of alcoholics are more likely then to develop into alcoholics themselves. Therefore, 
studying alcoholics and their behaviors is necessary as it impacts relationships in a neverending cycle of alcoholism.

\section{Adjusting to the Alcoholic}

Some of the earliest family research investigated how families adjusted to an alcoholic member. Typically, a family is able to agree when an alcoholic disorder is present (Slutske et al., 1996). Identifying the drinking problem may be necessary as research indicates that the alcoholic's personality traits can transpose to other family members (Day, 1961; Parsons, 2003) and that the family environment is disrupted (Rangarajan, 2006; Rangarajan \& Kelly, 2006). Behaviors and communication practices are altered. Engaging in behaviors such as not talking about the current situation and being indirect with communication behaviors are learned patterns that become functional behaviors for family members (Gravitz, 1985). Researchers (Ackerman, 1986; Jackson, 1954, 1956) indicate that these behavioral changes happen in stages including denying the problem, attempting to eliminate the problem, experiencing feelings of disorganization, attempting to reorganize in spite of the problem, separating from the alcoholic, reorganizing the family without the alcoholic, and reorganizing as a collective unit with the alcoholic once sobriety is achieved. Each of these stages is characterized by unique interactions and communicative events that represent many families' experiences. Jackson (1954) was the first to identify the stages of behavioral change that can occur in the alcoholic home. Initially, the marital unit reacts to the alcoholic's drinking by attempting to deny the problem. This denial typically stems from inappropriate behaviors occurring in a social situation (Jackson, 1954). Neither the alcoholic nor the spouse wants to admit to having some sort of problem. Typical to most research, the 
husband is the alcoholic partner while the wife is the nonalcoholic partner. The husband and the wife try to explain the behaviors and rationalize the actions. Attributing the drinking to some other influence such as a stressful job or difficult marriage are common ways of reasoning drinking patterns (Ackerman, 1986).

Gradually, the wife realizes the problem exists. This realization then leads to the development of the second stage. The second stage begins when individuals attempt to eliminate the problems associated with drinking. In this stage, social isolation is not uncommon and attempts to "cover up" the problem increase (Jackson, 1956). The couple may choose to explicitly communicate about the alcohol problem with each other. The wife undertakes efforts to communicate about alcoholism (Ackerman, 1986). However, the explicit verbal communication of a problem usually does not proceed smoothly. As a result, the alcoholic distances himself from others, and family members experience increased frustration and agitation with each other.

The third stage is disorganization. In this stage, the husband makes fewer attempts to control alcohol intake. The wife experiences increasing feelings of despair (Jackson, 1956). In this stage, individuals could cope with behavioral strategies such as avoiding the alcoholic and isolating oneself (Ackerman, 1986).

While these changes in the home are chaotic, the fourth stage begins when a cry for help to the alcoholic is made (Jackson, 1956). Any member of the family can extend the cry for help. This desire for help is associated with a desire for the family to survive (Jackson, 1954). During this stage, the wife takes charge of family functioning. The husband's alcoholic status has reduced him to the level of a child; thus, the wife takes on all of the husband's obligations (Jackson, 1956) and alters the traditional view of a 
family. The husband can have an intense positive or negative reaction to this. He may be motivated to reclaim his role as husband, father, and provider and subsequently reduce drinking behaviors, or his response could be volatile. The most disruptive events of this stage are the husband's attempts to get treatment and control his drinking (Jackson, 1956). It is disruptive because roles are shuffled between members of the family as they deal with the father's treatment (Ackerman, 1986). Next, the family also must reorganize once the alcoholic achieves and maintains sobriety (Jackson, 1956) by adjusting and renegotiating roles. Thus, while the alcoholic is working on sobriety, the other family members are in a constant state of flux and negotiation about each other's responsibilities. The mother has been taking care of the family because the father could not. Finally, now that the alcoholic father can once again manage family situations, he likely desires to be included and accountable for daily operations (Ackerman, 1986). As families transition through these stages, changes are occurring in family functioning, and the alcoholic can be a source of unpredictable behaviors (Ross \& McDuff, 2008; Rubio-Stipec et al., 1991). Dramatic circumstances present themselves and the family experiences increases in dysfunction (Clair \& Genest, 1987; Mothershead, Kivlighan, \& Wynkoop, 1998; Werner \& Broida, 1991). Issues such as conflict and lowered cohesion (Barry \& Fleming, 1990; Clair \& Genest, 1992; Dinning \& Berk, 1989; Jarmas \& Kazak, 1992; Johnson, 2001; Mylant, Ide, Cuevas, \& Meehan, 2002; Reich, Earls, \& Powell, 1988; Yeatman, Bogart, Geer, \& Sirridge, 1994), increased levels of family incompetence and abuse (Sheridan, 1995), lower amounts of family adaptability (Mylant et al., 2002) and emotional expressivity (Barnow et al., 2002; Jarmas \& Kazak, 
1992; Johnson, 2001), and lower levels of intimacy (Protinsky \& Ecker, 1990) are not uncommon experiences for members of an alcoholic family.

\section{The Family Climate}

Throughout these unpleasant times, Bennett, Wolin, Reiss, and Teitelbaum (1987) argued that the family environment is an important mediator in the emergence of alcoholism--that the people, behaviors, and actions inside the family unit impacted the development of alcoholism. One way researchers have investigated this idea is by examining how other family members respond and react to the alcoholic and his disease. Preli, Protinksy, and Cross (1990) found that family members of the alcoholic were able to adjust and accommodate new events in their environments. These adjusting behaviors can manifest in changing roles. When a role changes, behaviors are taken on that are not typical for that person. For example, a child could become the caregiver, give more emotionally, and take on more household responsibilities rather than the parents (Kelley et al., 2007).

While these changing roles allow for daily practices and routines still to occur, they negatively impact family members' feelings of solidarity with other family members, and an individuals' self-sufficiency (Jackson, 1958) and insecurity (Tomori, 1994). These experiences contribute to a tense, moody, miserable, and unreliable family (Callan \& Jackson, 1986). The climate in the family and among family members is important as it is associated with recovery from the drinking problem (Moos, Bromet, Tsu, \& Moos, 1979).

If the alcoholic's drinking patterns are predictable and members of the family are able to anticipate and determine the alcoholic's behaviors, higher levels of cohesion 
between the family members can result (Johnson, 2002). Moreover, if children have access to the non-alcoholic parent and a sober version of the alcoholic parent, the family experiences higher levels of expressiveness and fewer conflicts (Johnson, 2002). In essence, family members have to distance themselves from the drinking practices and be able to anticipate when binges occur in order to maintain some normalcy. Families that are able to disengage from the alcoholism in their family can proceed through daily life and even engage in family rituals (Wolin, Bennett, \& Jacobs, 1988). Keeping a familiar routine and engaging in family bonding experiences such as the sharing of rituals can impact children in healthy ways. In alcoholic families, if the family members engage in family rituals, conceptualize plans, and consistently carry out these plans, children living in these homes will function better (Wolin et al., 1988). Moreover, having these "normal" practices can increase children's self perceptions of ability to take control of situations (Bennett, Wolin, \& Reiss, 1988). These findings suggest that carrying out everyday routines is an important regulating factor in the alcoholic home (Hawkins, 1997; Steinglass, 1987).

\section{Types of Alcoholic Families}

Much like there are types of alcoholics, there are also types of alcoholic families. These family types are determined by the processes that occur within the family. Families that are able to disengage and continue with "normal" routines and typical family practices are labeled protective families (Haugland, 2005). A majority of families with an alcoholic do not fit into this family type, however. Other families are labeled emotional disruptive families. In these families, children are exposed to conflict and the other parent is impacted by their spouse's drinking (Haugland, 2005). An even more 
intense family experience can be found in the exposing and chaotic families. In these home environments, children witness a great deal of conflict and violence, and low levels of routines. In the chaotic family, individuals can even become victims of violence (Haugland, 2005). These typologies suggest that not all families with an alcoholic are the same and the types of experiences that the family members experience are not the same either (Bennett \& Wolin, 1990; Steinglass, 1987).

\section{Children in the Alcoholic Family}

Researchers (e.g., Kaufman, 1986) have argued for studying relationships outside the marital dyad, as the spouse of the alcoholic is not the only person affected by the alcoholic's behaviors. Once children are present in the alcoholic home, they too have a difficult life experience. Researchers have used two terms to describe children of alcoholics. Children of alcoholics can be referred to as COAs or ACOAs, adult children of alcoholics. A majority of research using the term COA has examined children who are toddlers through adolescence. When researchers use the term ACOAs, typically, they are referring to children above the age of 18 . However, not all research follows these guidelines (see, for example, Berkowitz \& Perkins, 1988; Drake \& Vaillant, 1988; Senchak et al., 1996). Moreover, studies (e.g., Domenico \& Windle 1993; Tomori, 1994) indicate similar results and experiences between children of alcoholics, those who are younger than 18 years old, and adult children of alcoholics, those older than 18 years old. As a result of these similarities, researchers consider the two groups together rather than making a distinction between the groups. Therefore, the literature on COAs and ACOAs is considered together, and the term COA is used to refer to all children of alcoholics, regardless of age. 
COAs are considered the population most affected by living with an alcoholic (Jackson, 1958). They learn unstable, highly inconsistent behaviors (Hecht, 1973), guess at what "normal" is (Woititz, 1986), and have a more distorted perception of reality (Hardwick, Hansen, \& Bairnsfather, 1995). Estimates indicate that the population of COAs is quite high. In the late 1990s, an estimated 28 million children in the United States were COAs (Walker, \& Lee, 1998). A large body of research has developed to examine how all of these children are affected by alcoholism.

The first descriptions of COAs were provided by clinicians describing their patients. Newell (1950) wrote three case studies based on young children's stories and experiences with an alcoholic parent. In these case studies, the children were exposed to erratic behaviors. There were times of increased affection and charming social interactions juxtaposing interactions full of ambivalence, frustration, and conflict. These chaotic environments have impacted children in a number of ways. From early accounts such as these, two major lines of research concerning children of alcoholics have developed. One line of research addresses the different roles children perform in the alcoholic home. Potter and Williams (1991) indicated that children in the family do not have the same experiences; they will adjust and are subsequently impacted differently by the alcoholic's behaviors. The second line of research examines these differences by uncovering the outcomes associated with being a product of an alcoholic family.

\section{Children's Roles}

There are several roles a child may play in the alcoholic home. The first role a child may take on is "the responsible one." This child takes care of himself/herself, other siblings, and the household chores. This child is also referred to as the "the family hero" 
(Deutsch, 1982; Wegscheider, 1981). These children are responsible and are typically high achievers. Other children become "the adjusters." These children become flexible and can adjust to events in the home (Black, 1986). They do not create excess work and instead adjust to whatever situation may arise. Finally, some children become the "the placater." These children are eager to smooth over conflict and develop into individuals that aim to please others (Black, 1986). Inherent to each of these roles are side effects such as lower self esteem, perceptions of cognitive competence (Johnson \& Rolf, 1988), and increased neuroticism and psychoticism (Beaudoin, Murray, Bond Jr., \& Barnes, 1997). Yet other research suggests that children may not be able to separate from the alcoholic parent because of fantasies that the home situation and alcoholic parent will miraculously become better (Berlin et al., 1988).

\section{Outcomes Associated with Being a COA}

By studying roles, researchers have highlighted the differences in children. Children will act and react to alcoholism differently. If multiple children are present in the alcoholic home, multiple roles are present. These role performances impact COAs in a number of ways, and a variety of outcomes are associated with being a COA.

Research conducted on outcomes can be separated into three categories: cognition, personality, and adaptation (Johnson \& Rolf, 1990). A majority of the studies assessing outcomes has used two populations as research participants. The first population is a collection of children from alcoholic families (i.e., they have at least one alcoholic parent), and the second is a group of children with no alcoholic problems or dependencies in their immediate family and serves as the control group. 
Cognition research has largely been informed by studies of COAs' scholastic abilities and behaviors at school. Performances at school are impacted by the alcoholism occurring at home. At a basic level, COAs have more difficulties with cognitive tasks (Bennett et al., 1988; Sher et al., 1991). One explanation for this is provided by Werner (1986) who indicated that COAs had less educational stimulation at home. As a result, COAs misbehave in school and cause disruptions. Their classroom disruptions come in multiple forms including conduct disorders, delinquency, defiant behaviors (Chassin, Rogosch, \& Barrera, 1991; Grekin, Brennan, \& Hammen, 2005; Ritter, Stewart, Bernet, Coe, \& Brown, 2002), and repeated absences (Drake \& Vaillant, 1988). When COAs are in school, they experience increased levels of communication apprehension (Fredricks, 1993), are less clear and less organized (Carter, Nochajski, Leonard, \& Blane, 1990), and have a more difficult time completing projects (Woititz, 1986) and concentrating on tasks (Woititz, 1983). Ultimately, the research on COAs' abilities at school suggests that school may be more difficult for them. As a result of these negative experiences in school, COAs have less positive perceptions about doing well in school and liking school (Johnson \& Rolf, 1988). These children also are less likely to connect to the school and to the education system (Mylant et al., 2002), which can contribute to lower vocational and educational goals (Tomori, 1994).

Unfortunately, the research on COAs not only indicates cognitive difficulties but personality difficulties too. The impact of living in an alcoholic home can create lasting impressions on how a child acts and interacts with others (Ackerman, 1987; Giglio \& Kaufman, 1990). COAs are less happy with their lives (Callan \& Jackson, 1986) and have lower levels of well-being (Baker \& Stephenson, 1995). They tend to have higher 
levels of anxiety (Senchak et al., 1996) and neuroticism (Benson \& Heller, 1987;

Kashubeck, 1994), lower levels of self esteem (Beaudoin et al., 1997; Bosworth \& Burke, 1994; Bush, Ballard, \& Fremouw, 1995; Currier \& Aponte, 1991; Rangarajan \& Kelly, 2006; Ritter et al., 2002; Williams \& Corrigan, 1992), are less independent (Whipple \& Noble, 1991), and have negative self concepts (Rearden \& Markwell, 1989).

These personality characteristics can impact a COAs' ability to interact with others. Children of alcoholics are less socially competent (Jacob \& Leonard, 1986). They feel as though they are unable to control interpersonal relationships (Hardwick et al., 1995). As a result, COAs are less agreeable, less conscientious, and less open to experiences (Jacob \& Windle, 2000). One result that can occur is receiving less social support (Domenico \& Windle, 1993). This can be especially detrimental as receiving social support is associated with lower stress (Terry, Rawle, \& Callan, 1995) and emotional reactivity (Bolger \& Amarel, 2007) in general.

The research on adaptation has produced similar negative findings. The home life of a COA has higher levels of parental distress (Bradley \& Schneider, 1990; Domenico \& Windle, 1993; Stout \& Mintz, 1996), which can impact a child. Adapting to a social situation is more difficult for COAs, and they often feel out of control and do not deal well with feelings of stress (Shapiro, Weatherford, Kaufman, \& Broenen, 1994). These children cannot wait for social rewards; rather, they have lower levels of self control (Shapiro et al., 1994; Sher et al., 1991; Tomori, 1994) and want immediate rewards (Eiden, Edwards, \& Leonard, 2004; Petry, Kirby, \& Kranzler, 2002). Perhaps the most consistent maladaptive finding in COAs is that they are more likely to suffer from 
depression or have depressive symptoms (Domenico \& Windle, 1993; Jarmas \& Kazak, 1992; Rolf et al., 1988; Rubio-Stipec et al., 1991; Tweed \& Ryff, 1991).

Taken together, it appears that the negative outcomes outnumber the positive ones and being the product of an alcoholic home has a harmful impact. Ultimately, being a child with an alcoholic parent contributes to the development of negative characteristics and relational processes. The negativity experienced in the family relationships and the poor relational processes learned in the family often extend to relationships outside the family unit.

\section{Relationships Outside the Family}

The alcoholic family often keeps a secret; they do not often share or acknowledge the drinking problem with those outside the family (Geddes, 1999). The members of the family encourage secrecy and denial as ways of coping (Black, 1985). The family members feel as though they must protect each other and are often embarrassed or fearful of encounters with individuals outside the family, especially when the alcoholic is present (Ackerman, 1986). The social stigma of alcohol abuse often results in isolation and separation of these families from those outside the family unit (Wilson, 1982). While the secrecy and denial behaviors can serve to protect and strengthen relational bonds inside the family they inhibit forming relationships with people outside the family and it is difficult for outsiders to get information (Karpel, 1980).

Research indicates that keeping the stigmatizing information a secret may be a wise decision. As many as $60 \%$ of individuals have reported negative attitudes towards problem drinkers and thought that people who could not handle drinking had weak character and lacked the ability to control themselves (Moore, 1992). These negative 
viewpoints extend to populations other than just the alcoholic. Burk and Sher (1990) indicated that the children of alcoholics are also stigmatized and viewed as deviants. Negative viewpoints such as these, arguably, work to silence alcoholic families. However, when the members of the family do engage in emotional disclosures with individuals outside the family, it can enhance the familial members' self esteem (Barrera, Chassin, \& Rogosch, 1993).

One type of relationship that has been researched is the relationship alcoholics have or form with other alcoholics. Typically these studies focus on the relationship built in rehabilitation centers or support group meetings. Once an alcoholic begins treatment or makes a decision not to drink, friendships with nondrinkers become increasingly important (Mohr, Averna, Kenny, \& Del Boca, 2002). As a result, relationships with friends and former drinking partners are often curtailed. Being part of a support group promotes the maintenance and continuation of a social network (Humphreys, Mavis, \& Stoffelmayr, 1994; Humphreys \& Noke, 1997). The support network shifts focus and is comprised of individuals dedicated to ending drinking behaviors. Moreover, these relationships have influence on the alcoholic and help the alcoholic to drink less (Groh, Jason, Davis, Olson, \& Ferrari, 2007), stop drinking for extended periods of time (Spinatsch, 1992), and promote the development of functional, everyday relationships (Orford, Hawker, \& Nicholls, 1975; Van Lear, 2006).

Alcoholics can have quality friendships (Humphreys \& Noke, 1997, Humphreys, Mankowski, Moos, \& Finney, 1999) and increased benefits from friendships (Humphreys, Finney, \& Moos, 1994). Although the friendships the alcoholics create are with individuals outside of the family unit, these relationships and the feelings of 
affiliation experienced in these friendships are similar to those relationships experienced among family members (Carlson, Dilts, \& Radcliff, 1994). These relationships also have positive outcomes such as increased happiness, reduced depression and anxiety (Li, Van Lear, \& Rangarajan, 2007), and more social support (Van Lear, Brown, \& Anderson, 2003). Individuals outside the family who have helped the alcoholic become sober are reluctant to end relationships with one another and may even become hurt and angry if they do end (Bell, 2007).

While it is clear that the alcoholic benefits from support group-type friendships, it is less clear how other members of the family benefit. When alcoholics share their counseling experiences with their spouses, a majority of spouses claim that it is a constructive experience and have a positive reaction (Burton \& Kaplan, 1968). However, the same positive benefits are not experienced across familial relationships. Research suggests COAs in support groups experience more negative feelings, attitudes, and behaviors with regard to parental alcoholism as compared to those not in support groups because they have been able to share and process their experiences in the alcoholic home (Kashubeck \& Christensen, 1992). Thus, it appears that support groups are not ideal experiences for all members of the alcoholic home.

\section{Impact on Relationships}

For young adults, ages 16-25, from alcoholic homes, relationships outside of the family can be particularly difficult (Black, Bucky, \& Wilder-Padilla, 1986; Priest, 1985). Exposure to alcoholism lowers individuals' self-esteem (Beaudoin et al., 1997; Bosworth \& Burke, 1994; Bush et al., 1995; Currier \& Aponte, 1991; Rangarajan \& Kelly, 2006; Ritter et al., 2002; Williams \& Corrigan, 1992) and self concepts (Rearden \& Markwell, 
1989). The negative impact continues as individuals are significantly more likely to choose relationship partners who are themselves alcoholics (Schuckit, Tipp, \& Kelner, 1994). Once in a romantic relationship, those exposed to alcoholism experience lower levels of trust in partners (Bradley \& Schneider, 1990), are less open to feelings, have less intimacy and greater loneliness (Martin, 1995), and have negative attachment styles to their partners and relationships (El-Guebaly, West, Maticka-Tyndale, \& Pool, 1993). When COAs marry, they report lower levels of martial satisfaction than the norm (Kearns-Bodkin \& Leonard, 2008) and are more likely to get divorced and have multiple marriages (El-Guebaly, Walker, Ross, \& Currie, 1990). When communicating with others, COAs have difficulties expressing emotions (Barnow et al., 2002; Drake \& Vaillant, 1988; Jarmas \& Kazak, 1992; Johnson, 2001; Jones \& Houts, 1992), are less supportive and cooperative listeners, are less effective conversationalists, and more likely to pretend to listen to others when they are actually not (Grant, Rosenfeld, \& Cissna, 2004), and are dissatisfied with problem-solving communication (Harrington \& Metzler, 1997).

It appears that relationships for COAs are more difficult than for non-COAs; however, these relationships are important. If a COA is able to overcome the hardships of growing up in an alcoholic home, it can be attributed to sources of support outside the family (Werner \& Johnson, 2004). These outside-the-family relationships often have a profound, positive impact on the child (Perrin, 1985), and the child is more likely to feel positively about themselves and experience less adjustment issues (Ackerman, 1983). Thus, alcoholism creates a lasting impact that is felt across many facets of life. 
Those COAs living with the alcoholism experience declines in their overall health and with the ability to form functioning relationships and to become effective conversationalists. Families in which one member is an alcoholic have an inherently traumatic experience. Members of the family are negatively affected by the alcoholic, and the ramifications of being exposed to this type of individual affects life long processes. Given that the relationships individuals form with those outside the family unit can be a way for those in the family unit to overcome the adverse effects of alcoholism (Werner \& Johnson, 2004), disclosing information with others may be an important concept to investigate. Disclosing personal information can be a way for individuals to seek help from others, experience catharsis, and educate others (Derlega, Winstead, Mathews, \& Braitman, 2008). One theory that explains the disclosing process of private information is Petronio's $(1991,2000,2002)$ Communication Privacy Management Theory.

\section{Communication Privacy Management Theory}

Communication Privacy Management Theory (CPM; Petronio, 1991, 2000, 2002) provides a useful framework to understand the processes that occur when one is deciding to reveal or conceal information. CPM is a rule-based theory that focuses on the revealing and concealing processes an individual uses to share private information.

In order to understand the ways people make decisions about what to do with private information, it is necessary to consider private information a commodity that can be owned by people, shared with others, and negotiated for use. According to CPM, revealing and concealing private information is dependent upon the intersection of boundary structures and a rule-based management system (Petronio, 2000). The theory 
outlines six processes individuals use to control the flow of information. These processes include (a) owning private information, (b) controlling the private information, (c) controlling who knows the private information, (d) sharing and co-owning the information, (e) agreeing upon privacy rules with another party, and (f) dealing with any disruptions in the privacy rules (Petronio, 2002; Petronio \& Reierson, 2009). These six processes undergird two components of CPM: boundary structures and rule management processes. The boundary structures provide the foundation for revealing and concealing information and underpin the rule management process, but it is the rules that make the management process work (Petronio, 2002).

\section{Boundary Structures}

Boundary structures are composed of four components: ownership, control, levels of control, and permeability. When an individual perceives information to be something he/she possesses, an individual is experiencing ownership. Private information is thought to belong to the individual and as a result is controlled by that person; the process of revealing, concealing, and managing information is done by those with ownership. Petronio (2002) indicated that people want to control the flow of the information. The flow of information is managed in two types of boundaries--personal and collective boundaries. These are levels of control. Personal boundaries include any information that is known only by the self, while collective boundaries include information that has been shared with others or information that others have shared with us. Thus, once information is shared, it no longer belongs solely to the individual. Instead, it is now coowned. 
Collectively owned information is managed by all those with knowledge of the information (Petronio, 2002). At any given time, individuals are managing personal boundaries for information that only they know and collective boundaries for information in which they are part of an ownership team. Once information is known, a metaphorical boundary is created around the information. This boundary surrounds the information and safeguards it from others. These boundaries are managed on varying levels of permeability. Boundaries can be permeable or impermeable. That is, the metaphorical boundary surrounding some private information may be relatively porous and information is more freely able to proceed through the boundary (i.e., disclosed). However, other information is highly safeguarded by an impermeable boundary through which limited, if any, information is revealed to others.

The privacy boundaries each co-owner erects around the different types of information will vary in permeability; that is, certain targets will know more while others will know less about the information. Research indicates that individuals share more with family members (Caughlin et al., 2000) or with those directly involved in the experience (Sabee, 2008) and will thus share a more permeable boundary.

Regardless of whom individuals share information, the four boundary structures work together to influence the rule management processes that are used. The boundary structures detailed by Petronio (2002) provide only one way to understand how individuals deal with private information. In addition to the boundary structures, Petronio identified rule management processes. These processes become increasingly necessary as individuals receive information. It is important to note that managing private information occurs on both the individual and collective level. That is, private 
information that belongs only to individuals is managed on a personal level while information that belongs to more than one individual is managed on a collective level. Once a disclosure is made, there is a "need for boundary coordination because there is an expected guardianship of the information often assumed by both the discloser and the recipient" (Petronio, 2002, p. 11). The management process is used to determine how private information is regulated by those who own the information (Petronio, 2000).

\section{Rule Management Processes}

The boundary structures undergird rule management processes. As individuals develop rules through which to manage the flow of information, the aforementioned boundary structures are used as a foundation. They promote the creation of privacy rules that are then used to provide access to information. The rule management process contains three distinct components: privacy rule foundations, boundary coordination operations, and boundary turbulence.

Privacy rule foundations. The first management process outlined by CPM is privacy rule foundations (see Figure 1). Rule foundations include two features: development and attributes (Petronio, 2002). When a privacy rule is developed, it is created or established. Access rules to private information are developed along several criteria including culture, sex and/or gender, motivations, context, and the risk-benefit ratio. These criteria inform and shape the types of boundaries and revealing and concealing processes an individual uses. 
Figure 1. Management Process One: Privacy Rule Foundations

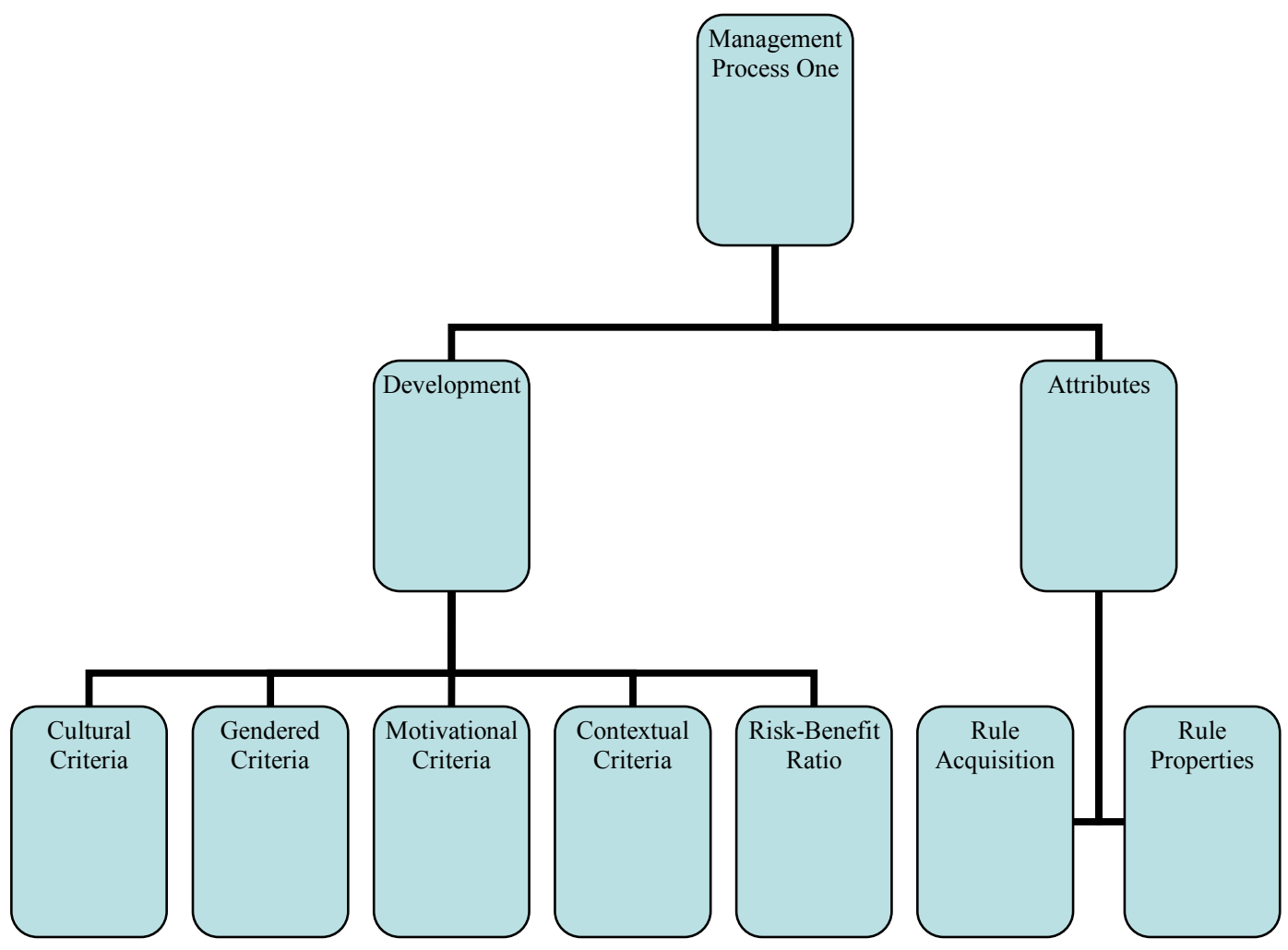

Three criteria-cultural, gendered, and motivational-are personal characteristics that can impact development of rules. First, an individual's cultural background influences how much private information is revealed to others. Cultures have different values about privacy and as a result, these influence how individuals manage disclosing information. For example, individuals from high context cultures would not disclose the same type or amount of information as those from low context cultures (Gudykunst, 1983). Second, an individual's sex affects how information is managed. Men and women expand their privacy boundaries based on differing criteria; because they have differing criteria, they create unique privacy rules that are not similar (Petronio, 2000). For women, the situation becomes important. While women generally disclose more than men (Koesten, 2004), some CPM research indicates that women are less likely to disclose than men, especially when encountering a new situation (Gibbs, Lai, \& Ellison. 2009). 
Third, an individual's level of motivation affects rule development. A number of motivations drive an individual's desires to give access or protect private information (Petronio, 2000). For example, people may be motivated to reveal more to others because they feel attracted or lonely or because they have a need to control or a desire for catharsis (Petronio, 2000; 2002).

Two additional criteria-context and risk-benefit ratio-are important elements that individuals must consider. The context or circumstances people find themselves in can impact the types of rules they use to reveal or conceal private information. Life events such as traumatic events, therapeutic situations, and life circumstances can alter the way a person needs to reveal and conceal information. Also, the risk-benefit ratio is necessary to consider when making a decision to disclose information. There is a need to balance the costs and rewards of revealing private information (Petronio, 2002). Based on this ratio, decisions are made and rules are developed that help maintain this balance. The perceived stigma can influence the risk to reward ratio. Stigma risk involves revealing information that could potentially discredit an individual. Vangelisti (1994) found that when a person predicts a negative evaluation of the information to be revealed, the revealer will more likely not disclose to those outside of the family and may not even tell the family.

CPM research which focuses on boundary structures, indicates that culture, gender, motivation, context, and risk-benefit ratio are all important considerations across a number of contexts including teacher-student relationships (Hosek \& Thompson, 2009), online disclosures (Catlett, 2007), and workplace communication (Allen, Coopman, Hart \& Walker, 2007). An additional criteria not identified by Petronio (2002) was that of 
past experience. In this category, Hosek and Thompson (2009) indicated that previous experiences were helpful in forecasting how individuals would disclose in the future.

Ultimately, rule development depends on the aforementioned five criteria. Using these criteria, rules are constructed or changed based on the needs of the situation. Also a part of the first rule management process is that of privacy rule attributes. Once the rule is developed, it has two key dimensions: acquisition and properties. When people learn of a rule or are socialized into a preexisting rule, they are said to have acquired a rule. Individuals learn pre-existing rules (Petronio, 2002). For example, when an individual joins a family, as in the case of marriage, the person learns all the family rules that were originally unknown by the person. Individuals can gain rules through socialization with other individuals or negotiation with others about rules. Additionally, rule properties are the qualities of privacy rules and help to describe the type of rule. Rule properties illustrate if the rule is a routine action or a response to a conversational stimuli. Taken together, rule acquisition indicates how the rule becomes known by individuals and the rule properties are the unique characteristics of that rule.

Boundary coordination operations. The second rule management process Petronio (2000; 2002) outlines is boundary coordination operations (see Figure 2). In this management process, individuals make decisions about what they choose to reveal and conceal. When individuals change individual boundaries into collective boundaries (i.e., they disclose private information to others), a carefully coordinated system of boundary linkages, ownership, and permeability are utilized. Collective boundary management is dependent upon these three processes. First, individual boundaries are managed in such a way that linkages with others can be made that change an individual 
boundary into a collectively owned boundary. Second, boundaries are regulated in such a way that access or protection is allowed to certain types of information. This boundary permeability is an important part of the process as it determines what information others are exposed. Third, boundary ownership is negotiated such that decisions pertaining to who is responsible for the information are made by those who now have access to the information.

This process occurs for both personal and collectively owned boundaries; however, the process involved in collective boundary management is more difficult as there are more parties involved (Petronio, 2002). Boundary coordination is accomplished by coordinating rules to allow for linkages, permeability, and ownership.

Figure 2. Management Process Two: Boundary Coordination Operations

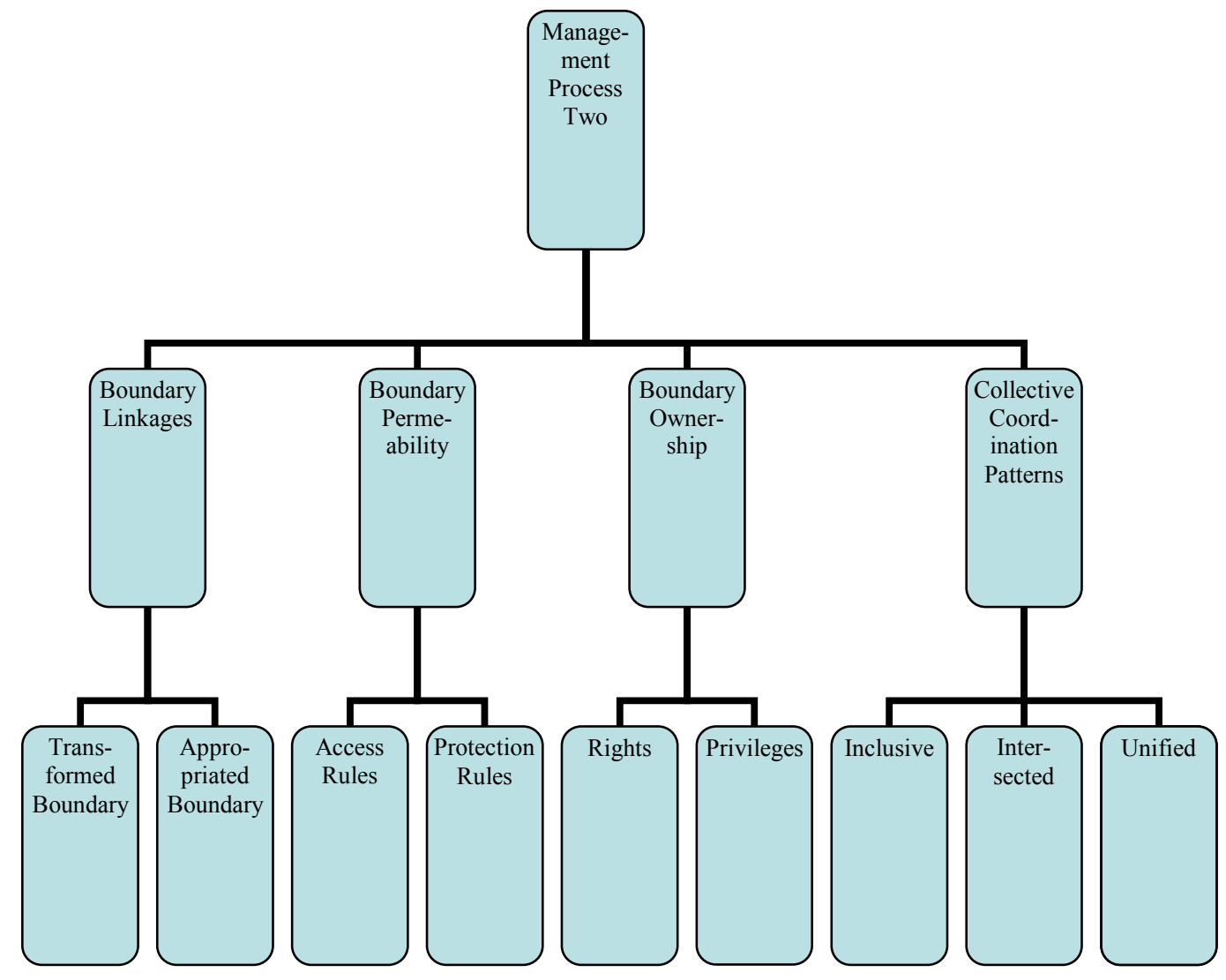


A linkage occurs when joining or converting one type of boundary into another type of boundary. A transformed boundary is the result of sharing information with an outsider; an individual confides in a confidant and reveals information. If an individual chooses a relationship partner and integrates the person into the family system, the once outsider now begins to acquire information as it is part of his/her membership in the family. This type of boundary linkage is called an appropriated boundary. Inherent to this linking process is the idea of permeability and the revealing of once private information and the resulting co-ownership.

The permeability of a boundary, or how much information passes through, is dependent upon the rules of access and protection. When access rules are enacted, more access to private information is granted. However, when protection rules are used, individuals will conceal private information. Thus, boundary permeability ranges from thin boundaries with open access to thick boundaries with limited access (Petronio, 2002). It is important to note that privacy boundaries will vary in permeability over time; privacy boundaries can oscillate between more permeability and less permeability such that information is loosely controlled or tightly controlled (Bute \& Vik, 2010).

Once boundaries become dyadic or collective, the members who own the information need to regulate access to the private information (Petronio, 2002). This process is done through negotiating privacy access rules. Those with the information must determine who else can become aware of the information. When access is granted to private information, a number of factors are considered including the the nature of a situation and sex of the target (Durham, 2008), age and physical environment (Thorson, 2009), and a positive, personal relationship or shared similar experience (Hosek \& 
Thompson, 2009). Additionally, when individuals feel attraction to a conversational partner, they will be more inclined to disclose; however, when the information to be disclosed is stigmatized, individuals will be less likely to disclose (Polk \& Hullman, 2008)

"Boundary ownership refers to rights and privileges individuals perceive they have and others accord them as co-owners" (Petronio, 2002, p. 30). When information is co-owned, both participants are aware of the privacy rules that protect the information. Once collective boundaries are formed, the owners of the information must coordinate their efforts to manage private information. The coordination patterns that emerge are the result of the co-owners synchronizing their efforts to manage the private information (Petronio, 2002). People can have differing opinions on ownership. Individuals can perceive information to be theirs alone while others feel as though the same information is co-owned.

Three general patterns emerge: inclusive, intersected, and unified boundary coordination. An inclusive boundary focuses on the exchange of power. One person gives complete privacy control to another person. This person will then manage more of the other's privacy. Inclusive boundaries can be the result of pressuring an individual to disclose, when individuals take a role that dictates he/she gets to have more power, or are the result of an individual sharing more information than the confidant (Petronio, 2002). Parents have control over a young child's private information because of their role as a parental guardian. An intersected boundary occurs when an equal amount of private information is exchanged between two people (Petronio, 2002). Over time, the two individuals share nearly equal amounts of information; their patterns of revealing and 
concealing are not identical, though they are similar in terms of breadth, depth, and amount shared. Individuals going through similar experiences may have intersected boundaries. Finally, a unified boundary showcases a pattern in which everyone owns information, not just one person. Once a member is part of a group, then he/she becomes an owner of the information. A family is an example of a unified boundary.

Boundary turbulence. The third rule management process Petronio (2002) outlines is boundary turbulence (see Figure 3). Boundary turbulence results when boundaries are not properly coordinated and can occur when boundaries are changed in established boundaries and when managing multiple boundaries (Petronio, 2002). Thus, boundary turbulence is the product of a mismanaged collectively owned boundary.

Boundary turbulence includes multiple forums such as (a) intentional rule violations, (b) boundary rule mistakes, (c) fuzzy boundaries, (d) dissimilar boundary orientations, (e) boundary definition predicaments, and (f) privacy dilemmas (Petronio, 2002).

Figure 3. Management Process Three: Boundary Turbulence

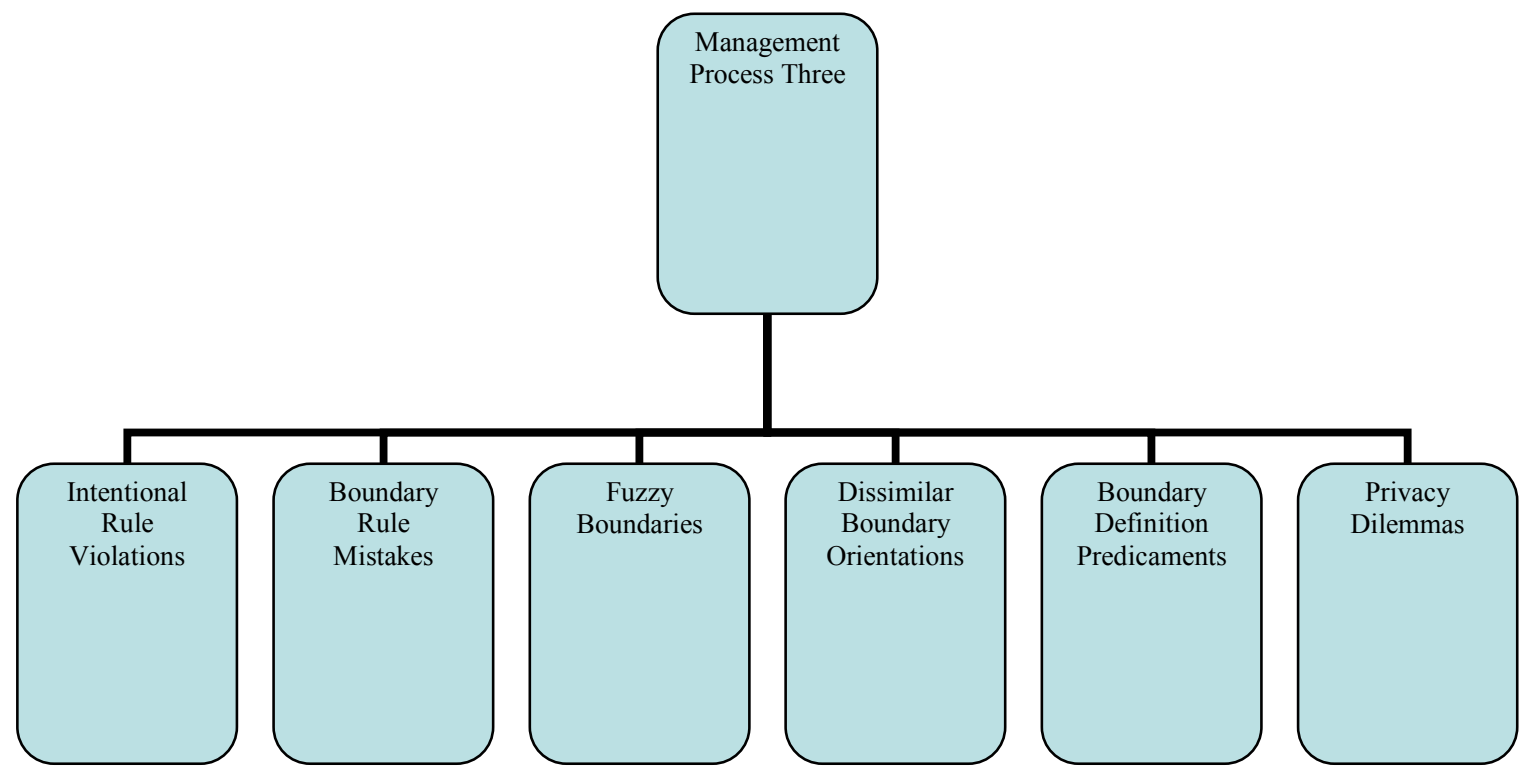


Intentional rule violations occur when individuals deliberately go against privacy rules. Conversely, boundary rule mistakes occur when individuals are not intentional in his/her actions and make an error in judgment about what should be done with the private information. Fuzzy boundaries are a result of ambiguous rules. Individuals are not certain of ownership or rules, and consequently, similar rule management processes are not used by all parties who know the information. Boundary turbulence can also result from dissimilar boundary orientations. These are an individual's orientations to privacy rules and in some situations will not change. If two people have differing orientations to privacy, they will experience turbulence as they work to negotiate rules (Petronio, 2002). Boundary definition predicaments occur when individuals in a collective boundary do not share the same definition for the border surrounding the private information. People may let others have access to the private information and inappropriately share information (Petronio, 2002). Finally, privacy dilemmas occur when an individual knows private information that should remain confidential, has the potential to cause problems, and may result in conflict when shared with others.

Collectively, boundary turbulence is present in many different forms in a collectively owned boundary. It is the result of a breakdown in management of privacy rules. While not necessarily pleasant, turbulence can contribute to discussions of boundary management processes and thus a renewed boundary management rules system.

\section{Rationale}

Westin (1967) indicated that privacy was an individual's claim to information with decisions about how and to what extent it is communicated with others made by the 
individual. Additionally, Petronio (2002) argued, "information is considered private when individuals perceive it as belonging to them" (p. 381). Thus, private information is something that individuals share with others at their own discretion, and until shared, it belongs to the individual. Adult children of alcoholics, arguably, feel as though their parent's addiction is private information. Socially, addiction is stigmatized and viewed negatively. Additionally, because once private information is shared, access to a person is granted (Tyma, 2007), it seems unlikely that COAs would freely discuss their parent's alcoholism. Rather, this information would be deemed private or as information only members of the family own because of the cultural stigma associated with alcoholism.

CPM is particularly situated to explain COAs' patterns of revealing and concealing information. Given the drawbacks of being raised in an alcoholic home, it seems intuitive that COAs would work to maintain some sort of boundary surrounding their experiences. Because alcoholism could be labeled a taboo topic and thus not openly discussed (Rankin \& Bustle, 2008), it is likely that COAs will make careful decisions about with whom they share information, what types of information they share, and what is done with the information once shared. These decisions and distinctions become increasingly important as boundary management is necessary as more people are included in a disclosive event.

According to CPM, individuals develop privacy rules based on a number of factors including cultural, gendered, motivational, and contextual criteria in addition to risk-benefit ratio. These criteria can be important considerations for COAs and the development of their privacy rules because when deciding whom to disclose to about difficult situations, it can be difficult to reveal information and stay honest with others 
while not frightening them (Weber \& Solomon, 2008). For the COA, the context in which the disclosive event occurs may be increasingly important. Highly personal information can be something that is closely guarded in public forums (Catlett, 2007), and if the information is not relevant to the situation, individuals will want the information to remain private (Allen et al., 2007).

Research indicates that individuals may be more motivated to disclose to certain people. When individuals feel attraction to a conversational partner, they will be more inclined to disclose; however, because the information to be disclosed is stigmatized, individuals will be less likely to disclose (Polk \& Hullman, 2008). It may be that COAs then experience a desire to disclose with those similar to them. CPM research indicates that individuals are more motivated to tell those in the immediate family and with those who have a perceived level of similarity (Durham, 2008). Additional parties may serve as the motivating factor to disclose such that third party influence can encourage the sharing of information (Epping \& Hammonds, 2007) or can even share the private information for the person (Niedermyer, 2008). A COA may then consider a host of criteria when creating privacy rules. Since little is known concerning the criteria COAs use to determine whether they should share information, the following research question was posed:

RQ1: What criteria (e.g., cultural, gendered, motivational, contextual criteria and risk-benefit ratio) do COAs use to develop privacy rules?

CPM argues that privacy rules have attributes. That is, they can be acquired and have properties. These are the two defining aspects of privacy rule attributes. They can be acquired through socialization or negotiation (Morr Serewicz \& Petronio, 2006). 
Families are not only important for socialization (Sillars, 1995), but they also teach individuals how to share private information (Catlett, 2007). For the COA, they are likely to be strongly influenced by their family members because those in the family know that an alcoholic is present in the family system and are thus part of the same community. Additionally, as children age, their behaviors can impact parents and both parties act as a catalyst for the behavior of others (Barratt, 1995). Thus, it seems likely that both parents and children are impacting the communication within the family unit. Additionally, privacy rules can have properties. Properties describe what type of privacy rule an individual is using. Privacy rules can be routines, that is the standard way to communicate about something. They can be adjusted to respond to different situational demands and are punishable if not followed. In order to examine the attributes of privacy rules, the following research question was posed:

RQ2: What are the attributes of the privacy rules used to guide the disclosure of a father's alcoholism?

It seems likely that COAs will be more open about their experiences in the alcoholic home with other family members. This is important because it can predict levels of satisfaction within the family (Morr Serewicz, Dickson, Morrison, \& Poole, 2007). With outsiders, however, CPM research indicates that family members must negotiate what they reveal (Western, 2008) or avoid disclosing and instead use conversational tactics to aid in keeping information private (Lev, 2008). These include providing inaccurate information that might be embarrassing to share; lowering vocal tones; indicating the private, sensitive nature of the information shared; and writing rather than verbally stating their disclosures. However, when information is shared and a link 
with another individual is formed, Weber and Solomon (2008) indicated this link can be a source of support. It seems likely that a COA would desire this support as their home environment is typically chaotic. A COA, however, may carefully craft the messages they send when making these linkages. McBride and Braithwaite (2008) indicated that the content of the message disclosed will be managed due to face concerns. In order to better understand the personal and collective boundaries COAs create, the following research question was posed:

RQ3: With regard to information about a father's alcoholism, what are the boundaries (i.e., linkages) that COAs create?

Two additional research questions were posed to examine how much information is shared and the resulting ownership decisions that are then made. The amount of information that is shared has been linked to a number of things including relevance to the context or situation (Allen et al., 2007), shared similar experience (Durham \& Braithwaite, 2009), levels of trustworthiness (Child \& Pearson, 2009), and the type of information shared (McBride \& Braithwaite, 2008). Generally, if the information is relevant to the context, individuals are perceived to be trustworthy, and the information to be shared is not traumatic in nature, more permeable boundaries are created.

Additionally, research indicates that those within the family unit, who are aware of infamily occurrences, may receive more disclosures as disclosing to outsiders could jeopardize how the individual is viewed by others (Derlega et al., 2008). It is important to note levels of permeability will vary over time. Bute and Vik (2010) indicated that boundaries shift over time with individuals becoming potentially more or less open, and that these shifting boundaries may be the result of contextual criteria such as 
experiencing prolonged life situations. Thus, it seems as though COAs would want to protect information about their alcoholic father; however, having a permeable boundary and talking with others is also needed and will likely occur with family members. COAs then must make decisions about sharing information and consider the costs of sharing information against concealing their negative family environment. Additionally, recipients can be reluctant. A COA could potentially observe this discomfort and as a result not share information with another.

For COAs, it is likely that information surrounding their parent's drinking patterns and behaviors is protected by an impermeable boundary. That is, protection rules will be used to keep information private. Arguably, protection rules are chosen over access rules because the alcoholic father can display unsavory characteristics such as withdrawing from others (Weiner et al., 1971) and not addressing the needs of others (Cornwell, 1968). Thus, COAs would likely have impermeable boundaries surrounding information about their alcoholic families. Research shows that when individuals do have a strong need to disclose they will likely use explicit, clear messages (Hollenbaugh \& Egbert, 2009). Thus, when COAs make decisions to disclose and share private information, they will consider access and protection rules and potentially use explicit language. If individuals disclose information and receive a positive reaction, the boundary permeability may increase (Western, 2008). In order to determine the level of permeability in COAs' boundaries and the subsequent ownership decisions, the following research questions were posed:

RQ4: With regard to information about a father's alcoholism, what are the qualities of COAs' boundaries (i.e., permeability)? 
RQ5: With regard to information about a father's alcoholism, how do COAs manage these boundaries (i.e., ownership)?

Finally, boundary turbulence can result when privacy rules do not operate as intended or anticipated (Petronio, 1991; 2002). As a result of sharing information, it seems likely that COAs may experience some conflict. First, sharing personal information can be unwanted by the family; instead, secrecy is advocated (see Black, 1985). Families feel protective of the alcoholic and may want to isolate themselves because of the stigma associated with alcoholism. Therefore, when other family members learn of a member's disclosures of shared information, it seems possible that conflict may occur. Ledbetter, Heiss, Sibal, Lev, Battle-Fisher, and Shubert (2010) found when parents invade children's private lives through verbal, online, and spatial strategies, children react in a number of defensive negative ways. These include avoiding the parent, concealing online conversations, and attempting to cause the parent emotional distress. That is, when children's privacy boundaries are invaded, their reactions are typically negative in nature and could result in conflict between the two parties. Moreover, as a result of these invasions, the boundaries that children erect can become reinforced; that is, the boundaries that are created are simply "the way it has to be" and children have to ultimately abide by the parents' rules (Stow, 2009).

An additional conflict that may occur is between the discloser and the target. When disclosing, the sender of the message is creating a linkage and extending ownership rights. Both parties are then charged with managing the information. However, given there are different orientations to privacy and different learned rules about privacy (Petronio, 2002), it is possible that the individuals may experience some 
kind of turbulence regarding the handling of the information. To explore this notion further, the following research question was posed:

RQ6: What types of boundary turbulence do COAs experience? 


\section{Chapter 1 Summary}

Alcoholism is a disease that is commonly thought of as consuming more than normal amounts of alcohol. It can be thought of as a family disease as it affects more than just the person with the drinking problem. Once exposed to an alcoholic, families must work to maintain family functioning. The highly dysfunctional alcoholic can negatively impact family members. While the entire family unit is altered by the presence of an alcoholic, the children in an alcoholic home are arguably most impacted. Relationships with individuals outside the family unit may be particularly difficult to form as those in the family unit have practiced separating themselves from others.

One way for COAs to work through the experiences they had while a member of an alcoholic family is to disclose information about their families to other people. While an inherently private, stigmatizing topic, sharing the information with others can serve a cathartic purpose for the COA. One theory that explains the revealing and concealing process is Petronio's Communication Privacy Management theory (CPM). CPM indicates that metaphorical boundaries guide the revealing and concealing processes around private information. Individuals work to manage the information using rule management processes. These processes include privacy rule foundations, boundary coordination, and boundary turbulence. These processes are carefully crafted by individuals as they move from personally owned information to collectively owned information. For COAs, the process through which linkages are made and ownership is shared is particularly intriguing as the private information they are revealing carries a large stigma. The present study focuses on understanding COAs' use of the three management processes of CPM. 


\section{Chapter 2}

\section{Methodology}

This chapter outlines the methodological considerations that guided the study. Included in the chapter is an overview of the methodological choice, a description of how I gained access and gathered willing participants to serve as interviewees, the interview procedures, and finally how I analyzed the data. The chapter concludes with a brief summary.

\section{Overview of Methodological Choice}

The present study employed qualitative methods. While quantitative methods have been used to assess COAs (see, for example, Kashubeck, 1994; Kashubeck \& Christensen, 1992; Stout \& Mintz, 1996), these measures fail to capture the lived experiences of the COAs. Moreover, these data collection methods fail to elaborate on processes COAs use when determining what to reveal and what to conceal about their parent's addiction. Also, the guiding framework, CPM, has widely been used to explain qualitative data.

When using qualitative methods, the researcher emphasizes process and a socially constructed reality with the primary focus on how social experiences are created (Denzin \& Lincoln, 2000). Moreover, qualitative methods focus attention on specifics of particular cases. Thus, this method was used because it allowed me the opportunity to investigate how COAs create, experience, and live the revealing and concealing process and provides COAs with an opportunity to express a voice that is often unheard in society. Additionally, making valid generalizations about COAs is difficult as alcoholics, and their families, are not a homogenous group (Sher, 1997). Alcoholics differ in a 
number of ways including the presence of a psychological disorder, age of onset, drinking patterns, and severity of dependence (Babor, Hesselbrock, Meyer, \& Shoemaker, 1994). COAs were asked to describe their father's drinking behaviors in an attempt to account for these differences. Qualitative research methods, thus, serve as a way to capture the lived experiences of COAs rather than attempting to make generalizations across all COAs. Ultimately, using this method is beneficial because it allows for the differences in alcoholics and COAs to be detailed.

While attempting to uncover the experiences of COAs and their decisions to reveal and conceal, four ethical codes guided my work including informed consent, deception, privacy and confidentiality, and accuracy (Christians, 2000). First, all participants gave informed consent. Each COA freely agreed to participate in an interview. Second, I fully informed all participants of the purpose of the study and briefed them about procedures and topics that would be addressed during the interview. Third, because the focus of the study was to understand the revealing and concealing of private, sensitive information, I also informed participants that the information they shared would be kept private and confidential. I removed all identifying information about participants and where interviews took place. I kept all transcriptions secure and shared with only those on the research team. Finally, I accurately transcribed the only face-to-face interview to ensure his story was provided. Moreover, because almost all interviews were completed via online messaging services (e.g., AIM, gchat), interviewees were able to put their experiences into their own words and phrases. As a result, I did not transcribe their interviews as interviewees were able to type their experiences in their own words. 


\section{Sampling and Recruitment Procedures}

Because this study focused on the experiences of adult children of male alcoholics, it was necessary to recruit individuals who grew up with an alcoholic father. This group served as the sample because most alcoholics are men (see Ackerman, 1986; Grant, 1998; Rubio-Stipec et al., 1991). Individuals could also participate in the present study if they grew up with an alcoholic stepfather, as long as the participant primarily lived with and was socialized by the alcoholic stepfather (i.e., those that lived only with an alcoholic stepfather on weekends, for example, were not included in the study).

Those who grew up with alcoholic mothers were not included in the sample. As previously noted, women tend to start drinking later in life and children may not have been present when the drinking occurred. Additionally, women have fewer drinking problems (Wilsnack, Klassen, Schur, \& Wilsnack, 1991), consume less alcohol, and have fewer alcohol-related consequences (Wilsnack, Wilsnack, \& Klassen, 1981). Because of this, I used a purposive sample, and I intentionally selected participants based on their meeting the inclusion criteria (i.e., identified as a COA, were above the age of 18 , had an alcoholic father or stepfather who is still alive, and lived at home with the father or stepfather while he abused alcohol) (Frey, Botan, \& Kreps, 2000). Due to the highly sensitive nature of the topic being discussed during the interviews, a network, or snowball, sample was employed as it is likely for COAs to not only know other COAs but also have spoken with them about their parent's drinking problems.

After I received Institutional Review Board approval, I actively recruited participants. Each participant self-identified as a COA. I gathered participants through a number of techniques including announcements made at Al-Anon meetings, social 
networking websites, and my personal network. Al-Anon is an organization that focuses on helping children of alcoholics understand their experiences, share their stories, and gain hope from other COAs (How will al-anon help me?, n. d.). Al-Anon considers alcoholism to be a family disease that impacts those surrounding the alcoholic. Attending an Al-Anon meeting is voluntary and free. All individuals who are COAs are welcome to participate in the meetings. I attended approximately three meetings a week in various locations including Morgantown, Clarksburg, and Fairmont. At the meetings, I actively participated in the reading of the Al-Anon steps and traditions and would share my experiences if asked. At the conclusion of the meeting, I asked a variety of a people about their interest in participating in the present study. In addition to asking individuals to participate, I also distributed an informational flier with details of the study and my contact information (see Appendix A). Leaders who organized the meeting recommended I speak with COAs individually rather than making a large, group announcement. While at the meetings, individuals shared their stories and experiences living with an alcoholic. By listening to their disclosures, I learned that most individuals at the meetings were either the parent of an alcoholic child or married to an alcoholic, and as a result, most were not eligible for my study.

I also gained participants through social networking websites. Social networking sites are an increasingly popular form of communication. I used Facebook to post a status (see Appendix B) that indicated a need for participants in the present study. Additionally, three of my Facebook friends posted the same status as their status. As a result, I was able to secure participation from a variety of resources. Finally, I used my 
personal network and contacted other COAs I grew up with or attended the same universities.

\section{Participants and Procedures}

The goal was to recruit as many participants necessary in order to reach theoretical saturation. Theoretical saturation occurs when no new information or concepts are identified during coding (Glaser \& Strauss, 1967). This has been accomplished in other CPM research after interviewing 12 (Durham, 2008), 13 (Catlett, 2007), 14 (Petronio \& Kovach, 1997), 32 (Durham \& Braithwaite, 2009), and 35 (Miller, 2009) participants. All participants in this study (a) identified as a child of a living alcoholic father or stepfather, (b) lived at home with the alcoholic father while he abused alcohol, and (c) were above the age of 18 years old. Participants indicated how long their father has been an alcoholic, the father's marital status, how long they lived at home with their father, how many siblings they have, when they learned of their father's alcoholism, and their experiences living in the alcoholic home. This information was necessary to consider when analyzing the experiences of the COA as it could impact the types of experiences COAs have had.

Participants in this study included 20 COAs (four males; 16 females). They ranged in age from 19 to 35 years old with an average age of 26 years old. Four of the participants reported living with an alcoholic stepfather while the remaining participants reported on their alcoholic fathers. All participants indicated that they had lived with the father or stepfather and that he was a primary socializing agent in their lives. Of the participants, three were my former students, six were professional contacts, and the remaining 11 participants were either my friends or individuals referred to me by others. 
Additionally, all participants indicated that the alcoholic father or stepfather had been drinking even before the participants could recall and as a result had been socialized in an alcoholic home through the duration of their lives. Participants lived in a number of states including Alabama, Illinois, Indiana, New Hampshire, New York, Texas, and West Virginia. The 20 interviews took an average of 93 minutes to complete, with the shortest interview lasting 59 minutes and the longest lasting 149 minutes. A total of 227 doublespaced transcripts were used in the data analysis. See Appendix C for more information about the participants.

This study used the family history method, a commonly used method in COA research. The family history method involves gathering data from a single family member about the existence of an alcoholic in the family (Windle, 1997). I interviewed each participant about his/her experiences as a COA. I used interviews as opposed to focus group discussions because of the sensitivity of the topic. During the beginning of the interview, I established rapport with my interviewees by talking about attending AlAnon meetings or discussing shared social network ties. Both before and during the interviews if participants asked about my own experiences, I shared personal information. Interview questions (see Appendix D) included communicating with members of the family and sharing information about the family's alcoholic to individuals outside the family. Consistent with past research (e.g., Petronio \& Kovach, 1997), I constructed the interview schedule in conjunction with principles from CPM.

I conducted the interviews at times and dates convenient to the participants. During the one face-to-face interview, I took notes of concepts that appeared to be particularly important to the interviewee. He gave permission to be audio recorded, and I 
transcribed recordings verbatim. I also told the online interviews that their words would be used verbatim and told to take time if necessary to think about their answers. They were also told they could "skip" any question as conducting the interviews online provided me with no nonverbal cues that could be used to determine participants' discomfort. I began analyzing transcripts for components of CPM while simultaneously collecting additional data.

\section{Data Analysis}

I subjected all transcripts to standard qualitative data analysis. I used a constant comparative method. That is, I collected and analyzed data simultaneously so that my interview guide may be further developed if necessary and so that I could work towards theoretical saturation (Glaser \& Strauss, 1967). Consistent with past research (see Durham, 2008; Miller, 2009; Petronio \& Kovach, 1997; Thorson, 2009), concepts from CPM directed data analysis. Moreover, Owen's (1984) three-part thematic analysis was used in this study. This method has been used in previous privacy management research (Epping \& Hammonds, 2007; McBride \& Braithwaite, 2008; Petronio, Flores, \& Hecht, 1997; Petronio \& Kovach, 1997; Petronio, Reeder, Hecht, \& Ros-Mendoza 1996; Petronio, Sargent, Andea, Reganis, \& Cichocki, 2004).

Using Owen's (1984) method for identifying themes, I used three criteria for determining themes in data: recurrence, repetition, and forcefulness. According to Owen, "recurrence is observed when at least two parts of a report had the same thread of meaning, even though different wording indicated such a meaning" (p. 275). Reports of the same basic meanings were first identified. I then looked for a repetition of key words. This criterion, repetition, is an extension of recurrence in that it strives to identify 
repeated word choices whereas recurrence focuses on implicit meanings. Finally, I examined the forcefulness of the data. Owen (1984) described forcefulness as vocal behaviors that emphasize certain parts of an individual's dialogue. These behaviors included vocal inflection, changes in volume, or pauses in speech. These were marked in transcripts by using bold and italic fonts and also including non-lexical cues such as filler words (e.g., uh, um). Because most interviews were conducted online, this aspect of Owen's (1984) method was not utilized in all coding. Some interviewees while typing used non-lexical cues while others did not. These included the use of phrases such as “uhhhh,” capital letters, exclamation points, and emoticons. The participants' experiences have been kept in their own words but grammar and punctuation have been corrected.

I read and re-read all transcripts and created a codebook (see Appendix E). The codebook contained CPM components that are relevant to the research questions guiding the present study. First, I trained one additional coder in CPM components and in Owen's (1984) coding process. The individual coded five interviews, or $25 \%$ of the data, while I coded the same five interviews. Intercoder reliability was then determined from the coding of this sample of data. Scott's Pi (Scott, 1955) was used to assess intercoder reliability. A reliability coefficient of .82 was achieved after coding $25 \%$ of the data. Because this coefficient was achieved, I coded the remaining data. 


\section{Chapter 2 Summary}

I used qualitative data collection principles to capture the lived experiences of COAs. These methods are particularly useful to understanding COAs as the alcoholic families from which they come are highly variable and lack consistent experiences, thus making it difficult to generalize findings across all COAs. Once I received approval from the Institutional Review Board, I began to gather participants. I recruited individuals to participate in the study from a number of sources including an individual from one AlAnon meeting, social network websites, and personal acquaintances. I interviewed participants about their experiences in the alcoholic home and how they share information with others. I continued this process until I achieved theoretical saturation which occurred after I interviewed 20 COAs. I transcribed the only face-to-face interview verbatim and used the participant's typed answers for data analysis. Using Owen's (1984) three-part thematic analysis, I subjected all transcripts to analysis. My interviews lasted an average of 93 minutes and yielded more than 220 pages of doublespaced transcriptions. I used components of CPM as the guiding framework for data analysis. I trained one coder and gave her $25 \%$ of the data to code while I simultaneously coded the same portion of the data. I assessed intercoder reliability using Scott's Pi and yielded a reliability of .82 . 


\section{Chapter 3}

\section{Results}

Robinson and Rhoden (1998) described COAs as invisible victims of a

devastating disease. For the 20 COAs interviewed in this study, they were provided with an opportunity to be made visible and illustrate how they describe the criteria, situations, experiences, and outcomes of sharing their experiences with others. Several themes emerged as important in the development of privacy rules, which is part of management process one-rule foundations. Rule development focuses on the way individuals establish privacy rules, and Petronio (2002) argued rules are based on culture, gender, motivations, context, and risk-benefit ratio. Of these, COAs in this study indicated that motivational and contextual critieria are the foundations for the rules they develop to manage the boundaries that regulate the revealing and concealing of information regarding their alcoholic father and experiences in an alcoholic home (RQ1). COAs indicated that they acquired rules by observing other family members and were thereby socialized by the family about what could and could not be discussed (RQ2).

Management process two, boundary coordination operations, focuses on making linkages, allowing for permeability in boundaries, and negotiating ownership. Typically, links are made with those individuals in the immediate family as they knew about the alcoholic father while the extended family and some outside family connections become privy to only certain types of information (RQ3). The amount of information shared, or the boundary permeability, differed based on the disclosure target. The type of information that COAs gave outsiders access to tended to be a collection of repeated stories that COAs deemed to be accurate depictions of what growing up with an alcoholic 
was like (RQ4). COAs did not engage in active negotiation of ownership rights because they did not feel like they had to ask confidants to keep information private; rather, it is simply implied that their trustworthy confidants who have been extended ownership rights will keep the information private (RQ5).

Management process three, boundary turbulence, focuses on the conflict surrounding the disclosing process. For COAs, boundary turbulence was not experienced as a result of sharing information about their alcoholic fathers because the information was shared only with trustworthy individuals. These trustworthy targets were perceived by the COAs to be confidants that would not share information with others and keep all information shared private (RQ6).

\section{Factors Impacting Disclosure Decisions}

Before I present the participants' experiences, it is necessary to share background information about COAs' alcoholic fathers/stepfathers. Fathers/stepfathers' alcoholism has framed COAs' experiences and impacted not only patterns of disclosure, but also, the COAs' entire lives. All participants (16 women, four men) reported on fathers/stepfathers that drank even before the child entered the home. The interviewees indicated that they gradually became increasingly aware of their father/stepfather's dependence. This awareness generally occurred when the interviewees were between the ages of 6 and 10 years. Of the 20 interviewees, 10 indicated that their father/stepfather still drinks while the remaining 10 indicated that their father/stepfather was sober. Fathers/stepfathers had been sober for as little as 2 months and as long as 20 years. The interviewees indicated that when their fathers/stepfathers drink, they not only drink various types of alcohol, but they also drink every day. Some of the alcoholics were quite 
functional as the interviewees noted that alcohol was just another part of their lives while other alcoholics neglected and ignored their families. The participants' experiences are presented next and organized by each research question. The quotes presented throughout are representative of the experiences had by the COAs in this study. While a number of quotes could have been selected for inclusion, the quotes presented best illustrated the theme with which they are presented.

\section{Management Process One: Rule Foundations}

Comprised of privacy rule development and privacy rule attributes, management process one focuses on the foundational elements that are necessary for individuals to create privacy rules orientations. During my analysis of participants' experiences, it became clear that male and female COAs developed different privacy rule foundations; therefore, gendered criteria is important to note before providing insight into their use of other privacy foundation elements. COAs in this study described two major criteria as important for the development of privacy rules, motivation and context. In terms of attributes, they also said they were socialized by family members and experienced situations in which they changed their privacy rules.

\section{Research Question One Results}

Research question one inquired about the criteria COAs used to develop privacy rules. Petronio (2002) indicated that individuals use cultural, gendered, motivational, and contextual criteria in addition to assessing the risk-benefit ratio. Noteworthy in the analysis are the sex differences that emerged. When interpreting the participants' experiences, it became evident that gendered criteria, as defined in Petronio (2002) were under-girding the participants' responses. Each male participant--Brian, Daniel, John, 
and $\mathrm{Josh}^{1}$--said that they rarely discussed growing up with their alcoholic father/stepfather. For these men, it was something that was in the past and was not addressed often. John and Josh each indicated that they only shared information with others if they were prompted by others. They indicated that they kept their experiences to themselves and only addressed the topic if others asked a question. Daniel said, "I usually don't talk about the situation a lot." Conversely, most of the female participants indicated being much more open about their experiences. Christy said, "I think I'm pretty open about the general fact that my dad is a recovering alcoholic. I mean, I don't shout it from the rooftops, but it's a big part of who I am." Other women also indicated that when deciding to reveal or conceal information, they always revealed. Diana said, "If it comes up in any way whatsoever, I just say it. Like if it pops into my head 'should I tell or not tell,' I always tell." Overall, the female COAs indicated being more willing to disclose and willing to share more details. This pattern is consistent with past research findings that indicate women generally disclose more information than men (Koesten, 2004; Mathews, Derlega, \& Morrow, 2006).

Participants in the present study indicated that motivations and context were key components of privacy rules development. COAs described factors that motivated them to develop privacy rules which included (a) communicating with others who have a similar experience and (b) sharing information with those individuals with whom the COA has an emotionally close relationship. Similar experiences and emotionally close relationships reoccur throughout the participants' experiences and are important to the revealing and concealing of private information. 
Petronio (2002) indicated that reciprocity in disclosure is one motivating force to share information. For COAs in this study, the reciprocity in disclosure emerged through sharing similar experiences. COAs indicated that they shared details with those who have had similar experiences and disclosed those situations. Jessica said she was more willing to share with those individuals who grew up with similar experiences: "I do have two close friends who have had alcoholic fathers so I talk to them pretty openly." Abby said, "If the person is experiencing the same thing and needs to know they are not alone, I share my story so they know they aren’t alone.” For Jessica and Abby, sharing information with others who had the same frame of reference and grew up with an alcoholic father/stepfather helped to create more open privacy rules.

The second motivating aspect COAs identified as a criterion for developing privacy rules that also was outlined by Petronio (2002) was liking. Petronio indicated that "if a person likes another, he or she may be more willing to disclose private information" (p. 54). For participants in the present study, this liking manifested itself as emotional closeness. COAs indicated they were often motivated to share information because they were emotionally close to an individual. Implicit to feelings of emotional closeness is a certain degree of liking. Elizabeth said she only shares her story of growing up with an alcoholic father with those emotionally closest to her: "Only the people closest to me know that story [about how she found out that her dad was an alcoholic], and other than that, I acknowledge the fact that my dad is an alcoholic.” Other COAs said that the emotional closeness contributed to the amount of disclosures a confidant received. Nora said, "My best friend knows everything. It's kind of like, the closer you get to me, the more you know." COAs did mention that this closeness can 
take time manifest. Nancy described this process as time consuming. "I guess I decide what's safe; what won't necessarily shock people. It takes a long time for me to disclose, to become close to people." It appears, then, from these experiences that COAs are motivated to share only with those individuals who are similar in nature or with whom they have meaningful relationships. COAs acknowledged that these relationships do take time to develop and, as a result, disclosures are not immediate.

Additionally, participants indicated that their privacy rule formation was undergirded by context. Specifically, COAs developed privacy rules based on the situation. If the COA was part of a conversation in which alcoholism or an alcoholrelated topic was discussed by others, COAs described using this conversation as a criterion for privacy rules. Nancy said, "If I hear that someone is in a situation with an alcoholic, that's when I want to share information the most." Lucy's experiences paralleled Nancy's when she said, "If anyone ever confides in me about a similar problem, I will almost always say, 'you know, I've been through very similar things, here's my story.'" Other individuals' discussions of alcohol acted as a catalyst for development of privacy rules for the COAs in this study. This finding further supports the importance of reciprocity in disclosure. Not only did COAs reveal information to those who could reciprocate because they had similar experiences, but they also revealed information because of the situation in which the COA found himself/herself; if others were discussing alcoholism, then the COAs would reveal information too.

Thus, in response to research question one, COAs develop privacy rules based on both motivation and context. They share with those individuals who have had similar experiences or with those individuals who they have developed emotionally close 
relationships. Additionally, COAs develop privacy rules once they find themselves in a setting in which others are discussing a topic related to alcoholism.

\section{Research Question Two Results}

Research question two examined the attributes of the privacy rules COAs use to guide their disclosures and focused on how COAs acquired privacy rules and the properties surrounding those rules. Consistent with research that indicates families are the primary means of socialization (Sillars, 1995), COAs indicated they acquired privacy rules through family socialization. They observed and then mimicked their nonalcoholic parent's behaviors. This acquisition occurred through a general observation process that did not require open discussion. The behaviors the COAs observed were of secret keeping. The families did not openly discuss the addiction; rather, keeping the alcoholism a secret was normal. Kim and Janie both indicated that they watched their mothers and used the same behaviors they did. Janie furthered her statement by adding, "We didn't really talk much about it." Another COA, Lindsey, said that alcoholism was not discussed and the impact it had on the family was also not discussed: "We [the immediate family] never really talked about what was going on and how it impacted anyone in our family." Emily added that this secretive nature contributed to ignoring the problem: "I think for a long time my family took the perspective that of if we don't talk about it, it's not a problem; when in all honesty, there was a problem." These COAs' stories illustrate a climate in which open communication did not occur; rather, they kept their father/stepfather's alcoholism a secret and continued to live in silence and ignore the problem. Daniel explained that talking about his father's drinking had a disturbing impact on other family members: "My sisters and mother are easily upset about my 
father's alcoholism so we don't discuss it very often." Thus, for some COAs, the secretive climate aided in ignoring the problem and helped family members act as if it was not something the family should address. In dealing with the alcoholism, other COAs' families became upset by the problem in the house.

It appears from these stories that a general sense of observation was used to understand what could be discussed. As a result of these observations, the alcoholic father's behaviors and the impact the behaviors had on family members was initially not discussed. A secretive climate was created. This type of secretive climate helped to deny the presence of a drinking problem. Scholars (i.e, Ackerman, 1986; Black, 1985) have indicated that this secretive climate is quite common because most family members do not want to discuss the problem; instead, they use silence as a way to suggest the problem does not exist.

Research question two also inquired about rule properties. While Petronio (2002) outlined several components of rule properties, only triggered rules are particularly salient for COAs in this study. Petronio described triggered rules as unpredictable situations, which are unplanned or new experiences that may trigger modifications to rules or the development of new rules. Participants said they experienced modifications in their privacy rules when the opportunity to create a connection with another COA occurred. These unplanned experiences occur when other COAs begin to share their stories.

The COAs in the present study then indicated that as a result of the others' sharing, they, too, began to reveal information, which once again supports the importance of reciprocity. Abby indicated that her privacy rules were changed when others were 
trying to share a story: "They [other COAs] are usually just coming to terms with their own experience so they are less comfortable talking about it for fear of judgment so I share my story so they know they aren't alone." For her, other COAs' discomfort in sharing of their own stories prompted her to share details. Christy offered an example of sharing more when someone inadvertently heard that she was a COA and began to divulge his/her own experiences. For example, she said,

I'm in a play and I was out with some cast members, and I offhandedly mentioned that my dad was in recovery, and my director immediately sort of, locked in on what I said and asked some questions and ended up sharing that his dad had died at 50 from alcoholism. And never got into recovery. Then you sort of start sharing war stories.

For the COAs in this study, their privacy rules were changed when others began to share their own stories and there was an opportunity to connect with others on a similar level.

According to Yalisove (2004), the COAs in this study were using experiential expertise because they used their own experiences to help other COAs develop an understanding of the occurrences in their own homes. Using this technique can be beneficial as they can use empathy to serve as role models for other COAs. This is important as it allows individuals to learn from others who had experienced similar problems.

Overall, rules are acquired through a general socialization process in which COAs learned to keep their father/stepfather's alcoholism secret. They did, however, experience triggered events in which they became more open to sharing information with 
others. When an opportunity to connect with another COA surfaced, the COAs in the present study disclosed their own experiences.

\section{Management Process Two: Boundary Coordination Operations}

When revealing and concealing private information, a number of issues must be examined. The second management process focuses on the linkages, boundary permeability, and ownership discussions that occur when boundaries are shifted or changed to include others.

\section{Research Question Three Results}

To start the examination of boundary coordination, research question three asked about the linkages COAs make with other individuals; that is, the research question focused on the connections that comprise the boundary alliance (Petronio, 2002). Participants indicated that several groups of individuals were given access to information about their father's alcoholism. These included individuals in (a) the immediate family, (b) the extended family, and (c) non-familial relationships. The individuals in each of these relationships, however, had varying degrees of knowledge about the father/stepfather's alcoholism. Individuals who were deemed emotionally close were the individuals COAs explicitly communicated to about their father/stepfather's alcoholism, and they were the ones who received greater depth and breadth of information. These linkages represent transformed boundaries. COAs shared information with trustworthy confidants thus altering the individuals who had access to the information. Other, individuals, however, especially those non-familial relationships, acquired knowledge about the alcoholism through observing the alcoholic. 
Every participant indicated that their family members who lived in the home had knowledge of the father/stepfather's alcoholism and had the most information concerning the events in the home as they were witness to the events. Participants indicated that those who lived in the home included their mothers, siblings, and step-siblings. These family members had working knowledge of all past events and kept the COAs "up-todate," according to Kristy and Polly, on any new events related to their father/stepfather's alcoholism.

Those extended family members also were aware of the father/stepfather's alcoholism. Jessica indicated that not only did her mother and sisters know, but her father's sister and her husband, her father's parents, and her mom's mother were also aware of her father's alcoholism. Polly indicated that everyone on her mother's side of the family knew about her father's alcoholism, as did her fiancé (although her future inlaws did not know about his alcoholism). Kristy said that her alcoholic father's siblings knew about his drinking problem. Those extended family members were likely aware of the problem drinking behaviors well before the COA was born as many COAs indicated that their father/stepfather started drinking long before they could remember. Therefore, it appears that a number of individuals in the extended family were aware of the alcoholism. While a number of extended family members might know about the alcoholism, how often it was discussed and what was shared varied. Nancy indicated that a majority of her family knew, but that it was rarely discussed:

The whole extended family [knows]. No one really talks about it though. Now that I think about it, not many people in the family know about the specific 
instances that came out of his drinking. It was made pretty clear in the immediate family that we didn't share a lot of that.

Nancy further described that this secrecy was a result of the embarrassment associated with his drinking and the negative events that can occur as a result of poor decisions (i.e., citations for drinking and driving). Collectively, it appears that a majority of family members had at least some understanding of the drinking problem that was occurring in the family. The amount to which it was discussed, however, did vary. The extended family was not highly informed of the occurrences in the home. It is likely that the climate of secrecy that was promoted within the family unit transferred to the extended family unit as well.

Non-familial individuals with knowledge of the problem drinking included friends, neighbors, and church families. Jessica explained that she told friends with whom she was close or with those whom shared similar experiences, thus echoing the findings for rule foundations. It makes sense, then, that if COAs are motivated to develop privacy rules based on having a positive, emotional relationship or having similar experiences, they actually engage in disclosure with targets who have these qualities. Jessica said, “The only people who know about it are my close friends and family. I do have two close friends who have had alcoholic fathers so I talk pretty openly." Several participants also indicated that their neighbors had a working knowledge of the events that occurred in their home because the COA would spend time in the neighbor's homes when the environment in their own home became too difficult to tolerate. These two linkages, friends and neighbors, were told about experiences or had a working understanding that something negative was occurring in the home, and as a 
result, the COA needed to leave the environment. The finally linkage that some participants indicated making was with those in their church. Those in the church family knew about the father/stepfather's drinking not because they were openly told, but because of their father/stepfather's behaviors. Jennifer indicated that a large number of non-familial relationships knew about her stepfather's drinking: "My church family knew. How could they not? My stepdad was at the legion every day and a wonderful lady from my church was the bartender, ha."

It is evident that a majority of the linkages COAs make with others are a result of forming emotionally close relationships or sharing similar situations. Although some research indicates that self-disclosure contributes to feelings of connection (e.g., Altman \& Taylor, 1973), it appears that COAs first need a level of emotional connection between themselves and the disclosure target. Being raised as a COA, it is likely that the child is aware of the negative stigma attached to alcoholism. Making decisions about forming linkages with others then and selecting only targets that have an emotionally close relationship makes sense as disclosing to individuals can jeopardize and impact perceptions (Derlega et al., 2008).

\section{Research Question Four Results}

Research question four inquired about level of permeability of COAs' boundaries. Remembering that only those with similar experiences or who were deemed emotionally close received access to the private information, COAs indicated that they told "standby" stories (i.e., a collection of stories that they felt best illustrated their experiences being raised by an alcoholic father/stepfather and were routinely shared with others). Generally, the COAs described two types of stories: (a) stories that were less 
dramatic or situations they found to be somewhat humorous or (b) stories that were shocking in nature or very dramatic. Nancy described the stories as:

Not shocking: funny stories, standard, cursory info-that is, he drank a lot.

Shocking: he's forgotten to pick me up at school, the occasional punched wall during an argument with my mom. The real, serious dysfunction.

Although Nancy described both types of stories, overwhelmingly, COAs explained that the shocking stories were shared most; these types of stories were the "standby" stories that COAs shared.

Given that the shocking stories were the "standby" stories that COAs shared with others, it could be that COAs decided to share these experiences because in doing so they developed an increased sense of understanding in their experiences (Bochner, Ellis, \& Tillmann-Healy, 1997) and also experienced positive benefits in well-being (Pennebaker, Kiecolt-Glaser, \& Glaser, 1988). The non-shocking stories that were described as cursory information, were likely easier for the COA to process and as a result did not need to be shared with others to gain a better understanding of the event. Additionally, because the COAs were sharing stories with those who were emotionally close or had similar experiences, it is likely that these targets could help the COA process their experiences as they likely had extensive knowledge of the COA or had similar experiences.

Josh described one story that he shared with others because it occurred after a relapse in his stepfather's drinking behaviors. Josh said that after his stepfather began drinking after being sober for six years, the following incident occurred and is one he willingly shared with others: 
Then he started drinking again, except he was doing so at work and it was occurring frequently. He would call my mother up and tell her he couldn't drive home, and he would stay in his office. On my mom's birthday, he called and told her he couldn't drive home, hurt my mom real bad. His brother's wife came over and took care of my mom, and he [alcoholic stepfather] felt bad, so he came home anyway. I watched him walk in and play pinball with the hallway as he walked back to the bedroom, meaning he'd hit the left side of the hallway and bounce to the right and so forth. It was definitely something that I remember vividly. Christy's story echoes the negativity in Josh's story. Her experience occurred as she was achieving a milestone in her own life:

One [story she tells] is about the fact that when we were leaving for New York City to move me to college my freshman year; my dad was angry about something, probably about the fact that he was sad I was leaving, but he couldn't deal with the emotion so he just went for angry. We stopped at Walmart about five minutes from home, to pick something up, and my mom was like "you're drunk," and made him let her drive. I've told that story to both family and nonfamily. So it was this exciting life-defining moment, and he sort of ruined it for me.

While these stories are dramatic and traumatic in nature, the COAs admitted that these experiences were only a few of the events they witnessed growing up. Instead of sharing all their experiences, they used these "standby" stories.

Afifi and Steuber (2009) found that incremental disclosure, defined as revealing only pieces of secret information, is one way to reveal information about a sensitive 
topic. The COAs in this sample appear to be operating in much the same fashion by telling only the "standby" stories, thus using incremental disclosures as opposed to detailing all their experiences. COAs' entire life has been carefully guarded and kept secret; it was rarely, if ever, discussed with family members, and COAs made careful decisions about what to tell others outside the family. Thus, because their complete life experiences have remained secret, the "standby" stories were used as incremental disclosures because they are only part of the COAs' experiences.

Some participants indicated that their father/stepfather was a good person. Though they were sharing dramatic stories, they still felt compelled to add that their father/stepfather was a fine person who just happened to not be able to control his drinking. Caughlin, Afifi, Carpenter-Theune, and Miller (2005) indicated that individuals, when revealing secrets, carefully considered the outcome of sharing.

Specifically, they found that individuals were more likely to share their secrets if they would not be negatively evaluated and could maintain their relationship with the confidant. Thus, it appears as if the COAs, who in their sharing felt compelled to justify their father/stepfather's behaviors, were attempting to counter any negative outcomes.

\section{Research Question Five Results}

Research question five examined boundary ownership rights. COAs were asked to identify how they manage information once it is shared with others, thus addressing issues surrounding the coordination of boundary ownership rights. In doing so, COAs were able to discuss their perceptions of their chosen linkages' rights as co-owners. When discussing ownership, Petronio (2002) indicates there are two issues to consider: (a) who legitimately owns the private information and (b) who has control of the 
information. Although related, Petronio indicates that an individual can own private information while still not having complete control of what is done with the information. If individuals co-own information, it is a collective effort to then determine the borders surrounding the information. Interestingly, COAs indicated that they did not actively discuss what can be done with information. They perceived that they only told trustworthy people about their alcoholic father/stepfather and as a result do not feel like they have to ask them to not tell others. Rather, it is implicit in their telling that the target will not share the information with other people because they are trustworthy confidants. Janie said she did not ask others to keep her secrets, but instead felt it was implied. "I don't ask them to [keep information private], but I feel like they would do that, kind of an unwritten rule." Kim explained, "I think I just usually allude to the fact that I don't talk about it much. If I am talking to them about it, it is usually for a reason." COAs describe their confidants as keepers of information but discussing issues of control and actively negotiating what can then be done with the information does not seem to occur. Alexis indicated that these types of conversations did not occur because she "didn't really put rules on what can be done." Rather, COAs tell their confidants one of their "standby" stories and after sharing, do not actively negotiate ownership responsibilities. Thus, it appears that COAs view confidants as owners of the information, but explicit discussions of control and what can be done with the information do not occur. They view ownership as something that is relatively implied, that their confidants will just know to keep the information within the dyad.

As a result of COAs revealing information, two types of collective coordination patterns emerge. Because an intersected boundary occurs when an equal amount of 
private information is exchanged between two people, this boundary occurs when COAs are sharing information with other COAs. Both parties are revealing information about their experiences and reciprocate the disclosures. Also, because family members knew about the alcoholic father, a unified boundary was created. This boundary illustrates a pattern in which everyone owns information, not just one person. Once a member is part of a group, then he/she becomes an owner of the information.

\section{Management Process Three: Boundary Turbulence}

Petronio (2002) described boundary turbulence as the result of being unable to execute and enact rules guiding linkages, permeability, and ownership. Boundary turbulence comes in many forms including (a) intentional rule violations, (b) boundary

rule mistakes, (c) fuzzy boundaries, (d) dissimilar boundary orientations, (e) boundary definition predicaments, and (f) privacy dilemmas.

\section{Research Question Six Results}

Research question six inquired about the boundary turbulence that COAs experience as a result of sharing information. Turbulence results when issues of ownership are not properly negotiated or adhered to and is displayed in a number of ways including intentionally or deliberately sharing private information, accidentally sharing information, experiencing ambiguity about ownership rights, differing orientations to privacy, treating public space as private and thus inappropriately disclosing, or experiencing conflict or emotional grief as a result of knowing some private information.. None of the participants indicated experiencing boundary turbulence with their co-owned information. Of the 20 interviews, no one indicated that an informational recipient had experienced the boundary turbulence Petronio (2002) described, or any other type of 
boundary turbulence. Most participants claimed to be unaware of any violations of the boundaries. Repeatedly, they responded that they did not have any conflict over the sharing of information to others because they disclosed information only to people they trusted.

Boundary turbulence likely did not occur because discussions of ownership did not occur between COAs and their chosen confidants. According to Petronio (2002), turbulence is the result of an inability to "collectively develop, execute, or enact rules guiding permeability, ownership, and linkages" (p. 177). Thus, a key component of boundary turbulence did not occur at an explicit level that COAs could elaborate upon, and as a result, they could not provide insight into boundary turbulence. 


\section{Chapter 3 Summary}

Several important findings were gleaned from this study. COAs reported on their revealing and concealing of private information with individuals inside and outside of the family. Results indicated that COAs develop privacy rules based on emotional closeness and shared similar experiences. The context also helps COAs develop privacy rules as they are willing to reveal information if others are sharing details of a similar experience. They learn their privacy rules through family socialization, and they experience trigger events that impact their disclosure. Specifically, they disclose more if there is a chance for connection with others who experience similar situations. When COAs manage boundaries, they first make linkages with three groups of people: immediate family, extended family, and non-familial relationships. The level of permeability in these linkages varies and is based on levels of emotional closeness. Generally, the more emotionally close a COA is with an individual, the more access the recipient is granted to the private information. COAs typically had several "standby" stories-stories that are often told when sharing revealing information. These stories often illustrate the negative experiences that COAs encountered. Finally, COAs did not experience any boundary turbulence; rather, boundaries they created surrounding the private information are maintained by all those with ownership rights. 


\section{Chapter 4}

\section{Discussion}

From the results gleaned in this study, several general conclusions can be drawn about the findings and the effectiveness of CPM. First, the COAs in this study were socialized by their nonalcoholic mothers to keep their experiences private. Incidents related to their father/stepfather's drinking were not openly discussed. Given that COAs were socialized to keep secrets, having a confidant who could also keep a secret and not share information was important to the COA. COAs explicitly communicated about their experiences with a variety of audiences. They felt compelled to share their experiences with those they deemed emotionally close or shared a similar experience. Noteworthy in this finding is that the COAs in this study did not tell only those with an alcoholic parent. While they did share with others who had similar experiences, these were not their only targets of disclosure.

Instead it appears that the relationship was considered before COAs explicitly communicated about their experiences. Vangelisti, Caughlin, and Timmerman (2001) found relational security to be an important factor for revealing secrets. Specifically, individuals needed to feel as though they shared a trusting, close relationship with the individual before disclosing the secret. In carefully selecting these recipients, COAs reduced opportunities for negative evaluation (Vangelisti, 1994) and lack of acceptance (Vangelisti et al., 2001). Moreover, research indicates that sharing family secrets is associated with better psychological functioning (Jahn, 1995). In selecting these trustworthy targets, COAs ensured their personal, private information would remain carefully safeguarded by the confidant and experienced positive outcomes by sharing 
their private information. They selected confidants who they believed would not disclose to others, thereby negating opportunities for the COAs to be judged and viewed negatively by others.

Ultimately, these findings point to the importance of connection, whether in the form of emotional closeness or shared similarities, when confiding in others. Revealing and concealing information, it appears, happens as part of a natural process when individuals feel a link between themselves and the disclosure target. Once that connection is recognized by the individual, he/she then can engage in disclosive communication.

When considering the effectiveness of CPM to explain the COAs' experiences, some components did not adequately explain the COAs' decisions to reveal and conceal. Noticeably missing in the participants' experiences was a discussion of risk-benefit ratio. Specifically, participants did not describe considering stigma or face risks before sharing information. These two components, which are part of the rule foundations Petronio (2002) argues are used to create rules, were not present in this study, and yet both types of risks appear to be quite salient to this population given past research on alcoholism has identified it as a stigmatized illness that individuals do not share with others (e.g., Black, 1985). Because this is a noteworthy component of CPM and also something past alcoholism research has identified as a concern, there appears to be some disconnect. The COAs in the present study did not consider either of these aspects when sharing information. Perhaps, they did not address these issues as they were sharing information with those whom they deemed emotionally close. If this is indeed the case, it appears that emotional closeness and a sense of shared connection override feelings of stigma or 
face risks. That is, sharing similarities and having strong relationships are needed characteristics for open, honest disclosures free of judgment.

Additionally, coordinating boundaries and discussing ownership issues proved to be something that was nearly nonexistent in the COA sample in the current investigation. Discussions of what to do with information and who had control of information were largely implicit. COAs perceived their confidants to be trustworthy individuals, a feeling likely derived from their feelings of emotional closeness, and as a result, did not have discussions of ownership. According to Petronio (2002), discussions of ownership are an important component to this theoretical framework; however, that did not occur in this sample. Related to this, is a lack of boundary turbulence. While ownership discussions are a vital component of boundary turbulence, the two were not present in the COAs' decisions to reveal and conceal information.

\section{Theoretical Implications}

Based on the study's findings, there are several theoretical implications for CPM. These include further understanding of how stigmatized information is revealed, explaining prevalence of boundary turbulence, and refining components of CPM. First, the present study further supports the importance of understanding incremental disclosures when discussing sensitive, stigmatized topics to those outside the family unit. Consistent with Petronio et al. (1996), COAs had a series of "standby" stories they told; they told others only segments of their experiences. The "standby" stories were not exhaustive; rather, they were a snapshot of the experiences that COAs had growing up in an alcoholic home. This incremental disclosure, giving access to only parts of experiences in the alcoholic home, speaks to boundary permeability. It appears that these 
"standby" stories are surrounded by a permeable boundary while other stories are guarded by an impermeable boundary and protection rules. While COAs are communicating about their experiences, they are only allowing access to certain events and thus creating a climate of conditional permeability whereby only certain stories are told. Kuhn (2002) argues that the telling of stories is critical to the formation of individual identity and is impacted by the stories told and just as much by the stories that are not told. For the COAs in the present study, revealing the stigmatizing information by using incremental disclosures was how they created their identity to those outside the family. This helps advance CPM in adding more knowledge for understanding boundary permeability. Boundary permeability for those who share stigmatized information may be quite different than for those who share less stigmatized information.

Additionally, COAs stated they did not experience boundary turbulence as a result of sharing information with confidants. Individuals did not have explicit ownership discussions. As a result, it seems plausible that turbulence would occur in the form of fuzzy boundaries, which, according to Petronio (2002), are the result of ambiguity in ownership. However, COAs did not discuss any types of turbulence. Not only does being the recipient of sensitive information contribute to feelings of discomfort in the confidant (Coupland, Coupland, \& Giles 1991), but confidants also did not have discussions of ownership rights and actively coordinate boundaries with the COA. Thus, it seems as if turbulence may have been something experienced by the confidant as they were actively receiving sensitive information and were without rules to guide revealing and concealing of the sensitive information. 
Finally, participants in the present study were motivated to develop privacy rules based on emotional closeness. While similar to liking, emotional closeness is slightly different. Emotionally close relationships are likely those relationships in which emotional support, or expressions of concern, value, and acceptance (Cohen \& Willis, 1985), is received. Additionally, these relationships have a certain level of understanding, trust, disclosure, openness, and acceptance (Adams, 1986). Arguably, individuals whose relationships are emotionally close also like one another while those that like each other may not necessarily be emotionally close. Moreover, emotional closeness is significantly related to being selected as a confidant (Adams, 1986). Thus, this finding points to the need for further development of the motivations that undergird privacy rule development as liking appears to be only part of the motivation behind rule development and emotional closeness appears to be important to becoming a confidant.

\section{Practical Implications}

In addition to contributing to theory refinement, this study's results also have practical value. The findings gleaned are of particular import to three audiences: communication scholars, therapists, and support groups. The study's findings are important for communication scholars because they provide further insight into how, who, and when stigmatized information is revealed. Specifically, the study points to the importance of establishing emotionally close relationships before sharing information. Communication scholars should be particularly interested in emotionally close relationships as they can contribute to disclosing information and experiencing benefits as a result. 
Additionally, because COAs were socialized to keep their father/stepfather's drinking a secret and research indicates that sharing secrets can be benefical, communication scholars could design interventions or trainings for individuals dealing with alcoholism to communicate about their feelings, thoughts, and experiences. These should be targeted to the entire family unit as research indicates that working as a group to make sense of problems is the preferred method for treating COAs and their families (Robinson \& Rhoden, 1998).

Because COAs often deny their parents' drinking and cannot properly identify emotions associated with their parents' drinking (Robinson \& Rhoden, 1998), therapists and counselors could use the results from the present study as a way to understand what COAs are sharing with others and then attempt to question COAs about the emotions contained within those experiences. In doing this, a therapist or counselor would be helping COAs not only discuss their emotions but also make sense of any underlying issues.

Finally, and perhaps most importantly, the study's findings can help individuals in the alcoholic community. The study sheds light on how those encountering a stigmatized illness decide to discuss the disease. As a result, alcoholics and their families are provided with an outlet to share their stories and learn that they are not alone in their experiences. Additionally, members of support groups such as Alcoholics Anonymous and Al-Anon would benefit from this study. Upon reading the results from this study, individuals attending Alcoholics Anonymous, a group dedicated to helping those with alcohol dependency, would gain insight into how their actions impact their families, how their alcoholism is talked about, how it is shared with others, and the outcomes their 
families experience as a result of sharing information. Members of support groups such as Al-Anon would benefit from learning that others have experienced similar situations and take comfort in learning from others' experiences.

\section{Limitations}

While this study adds to existing literature which focuses on revealing and concealing stigmatized information, there are some noteworthy limitations including issues related to data collection procedures and participants' demographics. First, 19 of the 20 interviews occurred online. Although this method is growing in popularity and is viewed as a valid and reliable means of gathering data, particularly about sensitive topics (Lannutti, 2009), and has advantages such as accessing individuals who are geographically separated, providing anonymity not typical of face-to-face communication, and offering respondents the opportunity to create well-crafted answers (Opdenakker, 2006), it also has disadvantages. Specifically, interviewers are without cues such as facial and environmental cues and cannot gather nonverbal cues that may signal discomfort or misunderstanding (Opdenakker, 2006). Thus, there is an increased chance for miscommunication because these cues are lacking. Of these disadvantages, missing facial cues and increased chance for miscommunication have the potential to create a significant impact on the research. Given the sensitivity of the topic and the negative experiences many of the COAs had, having facial cues and hearing their vocal tones could have contributed to the number and types of questions asked. By observing expressions and hearing vocal tones, I may have asked different questions, skipped particular topics, or further probed certain topics. These cues could become increasingly necessary to observe for future studies. 
Another limitation of the present study was that the COAs interviewed were highly educated. Of the 20 individuals I interviewed, at least 12 had completed a Bachelor's degree, with some of the interviewees completing Master's (4 individuals) and Ph.D. (3 individuals) coursework and degrees. Given that past research has found COAs to struggle in school and with cognitive thinking (Bennett et al., 1988; Sher et al., 1991), the COAs interviewed for the present study are clearly not the typical COA. In completing as much education as they had, the participants were not typical of previously studied COAs, whose cognitive thinking skills had been negatively impacted by the living in an alcoholic home (see, e.g., Bennett et al., 1988; Sher et al., 1991). Those interviewed for the present study represent a unique set of COAs, who to some extent have risen above the hardships of being raised in an alcoholic home to achieve an education. Additionally, the COAs I interviewed were not from Al-Anon meetings. Those who attended the Al-Anon meetings I attended were either married to an alcoholic or had children who were alcoholics. This is noteworthy because Al-Anon meetings could be considered a form of group therapy whereby individuals make sense of problems together.

A final noteworthy limitation in the present study was the use of CPM as a framework. Generally, the theory provided a sound foundation for understanding how COAs disclose information; however, parts of the theory did not fully explain their disclosing processes. Specifically, boundary turbulence did not speak to the COAs' experiences. While an important component of CPM, it was lacking in the present investigation. Future studies should note this lack of turbulence and adjust investigations to account for this. 


\section{Directions for Future Research}

Given the results of the present study, scholars can pursue a number of research avenues. These include addressing the need to justify and protect alcoholic fathers/stepfathers' reputation when disclosing sensitive information, further understanding ownership discussions, and understanding how the families create a climate of secrecy. When the COAs discussed sharing their "standby" stories, approximately five of the 20 interviewed indicated that they felt compelled to tell others their father/stepfather was a "good person." In the midst of their disclosures with confidants, the COAs said they would "stand-up" for the father/stepfather's reputation and assure the confidant that even though he was an alcoholic, he was still a good person that was able to "be there" for major life moments. Thus, based on the COAs in this study, there seems to be a trend to orally justify and protect the alcoholic father/stepfather and his reputation. Future research could use Afifi and Steuber's (2009) Risk Revelation Model (RRM) to further examine this protective trend COAs exhibited. In the model, the authors propose relationships between perceived risk of disclosing secrets and how the revealing process occurs. Key components to the model that parallel important features discussed by COAs include protecting others, having emotionally close relationships, disclosing only when in a certain situations, and selecting the information shared. Using this framework would expand the present study's findings because the model also investigates important features such as perceptions of risk in sharing the private information and communication efficacy.

Second, participants in the present study indicated that ownership rights and the management of information were not explicitly discussed with others; rather, they told 
confidants about their experiences and implicit in their telling, according to COAs, was a level of secrecy. It seemed that the targets of disclosures simply knew to keep the information to themselves. Therefore, discussions between COAs and their confidants on ownership and boundary coordination never occurred. Thus, the now collectively held boundaries were implicitly managed by both the COA and the confidant. It could be that the targets of the disclosure did not feel as though they truly owned the information. Especially for those targets outside the family, close friends, church members, and neighbors, they may have felt as if they were simply confidants who did not become owners of information. Instead, they may have felt like a vessel of information and allowed COAs to store their private information in the confidant. Future research could examine this by interviewing COAs' targets of disclosure. Understanding their perceptions of ownership would not only refine CPM, but it would also provide scholars with an understanding of the complete communicative process involving COAs and their confidants.

Finally, future research should concentrate solely on collecting information about growing up in the alcoholic home. This research could provide the necessary foundation through which to better understand the results gleaned in the present study. With this information, scholars and practitioners could better understand how COAs are socialized to conceal information and what these interactions of concealment look like. Further, some COAs indicated that once their own unique identities were secured, they deviated from patterns of secrecy learned in their homes. Thus, comparisons could be made between those learned patterns of secrecy and the potentially more open communication that occurs once a COA achieves certain developmental milestones. It may also provide 
context through which the patterns of revealing and concealing discussed by the COAs in this study could be understood. Additionally, it would shed further insight into how COAs experience a family identity and use the privacy rules that are acquired through their socialization process and how this group identity is then transformed and shapes personal identity once the COA begins his/her life independent of the family unit.

\section{Conclusion}

When considering the disclosing of highly stigmatized information, a number of conclusions about the participants in this study can be drawn, including how stigmatized information is disclosed, to whom it is disclosed, what information is disclosed, and the process that occurs once the information is disclosed. First, individuals develop very specific privacy rules that are be driven by motivations and context. Second, they disclose to individuals with whom they share an established, trusting relationship. These individuals can be family and non-family relationships, and the amount of information each of the targets knows varies. Third, for those with whom they do share details, COAs share a select group of "standby" stories. Finally, once told, COAs and confidants do not have explicit discussions of who owns the information and what should be done with it. Rather, it is the COAs' perception that the confidant knows the information should remain private between the two parties. As a result then, COAs and their confidants do not experience turbulence negotiating boundaries.

In sum, for the 20 COAs interviewed, the decision to reveal or conceal information about their experiences was highly personal and seriously considered. Although not diagnosed with the disease, alcoholism is a family disease and one that is experienced by all family members. While the fathers/stepfathers did the drinking, their 
actions forever changed the lives of the COAs in the study. Once COAs shared information with others, access was granted to an untypical environment; one in which fathers/stepfathers ruined special moments, entered the house drunk, disappointed nonalcoholic parents and children, and created a lasting impact on the lives of these 20 COAs. Thus, the present study starts to give voice and visibility to the millions of COAs who struggle with their family's addiction. 


\section{References}

Abrams, D., B., Binkoff, J. A., Zwick, W. R., Liepman, M. R., Nirenberg, T. D., Munroe, S. M., \& Monti, P. M. (1991). Alcohol abusers' and social drinkers' response to alcohol-related and general situations. Journal of Studies on Alcohol, 53, 409-414.

Ackerman, R. J. (1983). Children of alcoholics: A guidebook for educators, therapists, and parents. Holmes Beach, FL: Learning Publications.

Ackerman, R. J. (1986). Alcoholism and the family. In R. J. Ackerman (Ed.), Growing in the shadow: Children of alcoholics. Pompano Beach, FL: Health Communications.

Ackerman, R. J. (1987). Let go and let go: Recovery for adult children of alcoholics. Pompano Beach, FL: Health Communications.

Adams, R. G. (1986). Emotional closeness and physical distance between friends. International Journal of Aging and Human Development, 22, 55-76.

Adams, W. L., \& Cox, N. S. (1995). Epidemiology of problem drinking among elderly people. The International Journal of the Addictions, 30, 1693-1716. doi:10.3109/10826089509071053

Afifi, W. A., \& Caughlin, J. P. (2006). A close look at revealing secrets and some consequences that follow. Communication Research, 33, 467-488. doi: $10.1177 / 0093650206293250$

Afifi, T. D., \& Guerrero, L. K. (2000). Motivations underlying topic avoidance in close relationships. In S. Petronio (Ed.), Balancing the secrets of private disclosures (pp. 168-180). Mahwah, NJ: Erlbaum 
Afifi, T. D., \& Steuber, K. (2008, May). The “cycle of concealment” in families and strategies for revealing secrets. Paper presented at the meeting of the International Communication Association conference, Montreal, Canada.

Afifi, T. D., \& Steuber, K. (2009). The revelation risk model (RRM): Factors that predict the revelation of secrets and the strategies used to reveal them. Communication Monographs, 76, 144-176. doi: 10.1080/03637750902828412

Afifi, T. D., Olson, L. N., \& Armstrong, C. (2005). The chilling effect and family secrets: Examining the role of self protection, other protection, and communication efficacy. Human Communication Research, 31, 564-598. doi: $10.1093 / \mathrm{hcr} / 31.4 .564$

Alcoholics Info. (n.d.). Retrieved from http://www.alcoholics-info.com/

Allen, M. W., Coopman, S. J., Hart, J. L., \& Walker, K. L. (2007). Workplace surveillance and managing privacy boundaries. Management Communication Quarterly, 21, 172-200.

Altman, I., \& Taylor, D. A. (1973). Social penetration: The development of interpersonal relationships. New York, NY: Holt, Rinehart \& Winston.

Anderson, P., Wallace, P., \& Jones, H. (1988). Alcohol problems: Practical guides for general practices 5. New York, NY: Oxford Press.

Babor, T. F., Hesselbrock, V., Meyer, R. E., \& Shoemaker, W. (Eds.). (1994). Types of alcoholics: Evidence from clinical, experimental, and genetic research. New York, NY: New York Academy of Sciences.

Bailey, M. B. (Ed.). (1968). Alcoholism and family casework. New York, NY: Community Council of Greater New York. 
Baker, D. E., \& Stephenson, L. A. (1995). Personality characteristics of adult children of alcoholics. Journal of Clinical Psychology, 51, 694-702.

Barnow, S., Schuckit, M. A., Lucht, M., John, U., \& Freyberger, H. J. (2002). The importance of a positive history of alcoholism, parental rejection and emotional warmth, behavioral problems and peer substance use for alcohol problems in teenagers: A path analysis. Journal of Studies on Alcohol, 63, 305-315.

Barratt, M. S. (1995). Communication in infancy. In M. A. Fitzpatrick \& A. L. Vangelisti (Eds.), Explaining family interactions (pp. 5-33). Thousand Oaks, CA: SAGE.

Barrera, M., Chassin, L., \& Rogosch, F. (1993). Effects of social support and conflict on adolescent children of alcoholic and nonalcoholic fathers. Journal of Personality and Social Psychology, 64, 602-612.

Barry, K. L., \& Fleming, M. F. (1990). Family cohesion, expressiveness, and conflict in alcoholic families. British Journal of Addiction, 85, 81-87.

Beaudoin, C. M., Murray, R. P., Bond J, Jr., \& Barnes, G. E. (1997). Personality characteristics of depressed or alcoholic adult children of alcoholics. Personality and Individual Differences, 23, 559-567.

Bell, S. (2007, November). Narrative ethnography: The bridge between rhetoric and social science as revealed in a case study of persuasion in alcoholics anonymous. Paper presented at the meeting of the National Communication Association, Chicago, IL.

Bennett, L. A., \& Wolin, S. J. (1990). Family culture and alcoholism transmission. In R. L. Collins, K. E. Leonard, \& J. S. Searles (Eds.), Alcohol and the family: Research and clinical perspectives (pp. 194-219). New York, NY: Guilford Press. 
Bennett, L. A., Wolin, S. J., \& Reiss, D. (1988). Deliberate family process: A strategy for protecting children of alcoholics. British Journal of Addiction, 83, 821-829. doi:10.1111/j.1360-0443.1988.tb00517.x

Bennett, L. A., Wolin, S. J., Reiss, D., \& Teitelbaum, M. A. (1987). Couples at risk for transmission of alcoholism: Protective influences. Family Process, 26, 111-129. doi: $10.1111 / \mathrm{j} .1545-5300.1987 .00111 . \mathrm{x}$

Benson, C. S., \& Heller, K. (1987). Factors in the current adjustment of young adult daughters of alcoholic and problem drinking fathers. Journal of Abnormal Psychology, 96, 305-312. doi: 10.1037/0021-843X.96.4.305

Berkowitz, A., \& Perkins, H. W. (1988). Personality characteristics of children of alcoholics. Journal of Consulting and Clinical Psychology, 56, 206-209. doi: 10.1037/0022-006X.56.2.206

Berlin, R., Davis, R. B., \& Orenstein, A. (1988). Adaptive and reactive distancing among adolescents from alcoholic families. Adolescence, 23, 577-584.

Beseler, C. L., Aharonovich, E., Keyes, K. M., \& Hasin, D. S. (2008). Adult transition from at-risk drinking to alcohol dependence: The relationship of family history and drinking motives. Alcoholism: Clinical and Experimental Research, 32, 607616. doi:10.1111/j.1530-0277.2008.00619.x

Black, C. (1985). The family law in alcoholic homes-don't talk. In M. Miller (Ed.), Changing legacies: Growing up in an alcoholic home (pp. 39-42). Pompano Beach, FL: Health Communications.

Black, C. (1986). Children of alcoholics. In R. J. Ackerman (Ed.), Growing in the 
shadow: Children of alcoholics (pp. 105-111). Pompano Beach, FL: Health Communications.

Black, B. P., \& Miles, M. S. (2002). Calculating the risks and benefits of disclosure in African American women who have HIV. Journal of Obstetric, Gynecologic, \& Neonatal Nursing, 31, 688-697. doi: 10.1177/0884217502239211

Black, C., Bucky, S. F., \& Wilder-Padilla, S. (1986). The interpersonal and emotional consequences of being an adult child of an alcoholic. The International Journal of the Addictions, 21, 213-231.

Bochner, A. P., Ellis, C., \& Tillmann-Healy, L. M. (1997). Relationships as stories. In S. W. Duck (Ed.), Handbook of personal relationships: Theory, research, and interventions (2nd ed., pp. 107-124). Chichester, England: John Wiley \& Sons.

Bolger, N., \& Amarel, D. (2007). Effects of support visibility on adjustment to stress: Experimental evidence. Journal of Personality and Social Psychology, 92, 458475.

Bosworth, K., \& Burke, R. (1994). Collegiate children of alcoholics: Presenting problems and campus services. Journal of Alcohol \& Drug Education, 40, 15-25.

Bradley, L. G., \& Schneider, H. G. (1990). Interpersonal trust, self-disclosure, and control in adult children of alcoholics. Psychological Reports, 67, 731-737.

Brady, K. T., Tolliver, B. K., \& Verduin, M. L. (2007). Alcohol use and anxiety: Diagnostic and management issues. Treatment in Psychiatry, 164, 217-221. doi: 10.1176/appi.ajp.164.2.217 
Britton, P. C. (2004). The relation of coping strategies to alcohol consumption and alcohol-related consequences in a college sample. Addiction Research and Theory, 12, 103-114.

Burk, J. P., \& Sher, K. J. (1988). The "forgotten children” revisited: Neglected areas of COA research. Clinical Psychology Review, 8, 285-302.

Burk, J. P., \& Sher, K. J. (1990). Labeling the child of an alcoholic: Negative stereotyping by mental health professionals and peers. Journal of Studies on Alcohol, 51, 156-163.

Burton, G., \& Kaplan, H. M. (1968). Group counseling in conflicted marriages where alcoholism is present: Clients' evaluation of effectiveness. Journal of Marriage and the Family, 30, 74-79. doi:10.2307/350224

Bush, S. I., Ballard, M. E., \& Fremouw, W. (1995). Attributional style, depressive features, and self esteem: Adult children of alcoholic and nonalcoholic parents. Journal of Youth \& Adolescence, 24, 177-185. doi:10.1007/BF01537148

Bute, J. J., \& Vik, T. A. (2010). Privacy management as unfinished business: Shifting boundaries in the context of infertility. Communication Studies, 61, 1-20. doi: $10.1080 / 10510970903405997$

Callan, V. J., \& Jackson, D. (1986). Children of alcoholic fathers and recovered alcoholic fathers: Personal and family functioning. Journal of Studies on Alcohol, 47, 180182.

Carlson, H. B., Dilts, S. L., \& Radcliff, S. (1994). Physicians with substance abuse problems and their recovery: A survey. Journal of Substance Abuse Treatment, 11, 113-119. 
Carter, C., Nochajski, T. H., Leonard, K. E., \& Blane, H. T. (1990). Communicative competence in sons of alcoholics. British Journal of Addictions, 85, 1157-1163.

Cash, T. F., Briddell, D. W., Gillen, B., \& MacKinnon, C. (1984). When alcoholics are not anonymous: Socioperceptual effects of labeling and drinking pattern. Journal of Studies on Alcohol, 45, 272-275.

Catlett, J. (2007, November). An analysis of female university students' communicative management of privacy online via facebook. Paper presented at the meeting of the National Communication Association Conference, Chicago, IL.

Caughlin, J. P., Afifi, W. A., Carpenter-Theune, K. E., \& Miller, L. E. (2005). Reasons for, and consequences of, revealing personal secrets in close relationships: A longitudinal study. Personal Relationships, 12, 43-59. doi: 10.1111/j.13504126.2005.00101.x

Caughlin, J. P., Golish, T. D., Olson, L. N., Sargent, J. E., Cook, J. S., \& Petronio, S. (2000). Intrafamily secrets in various family configurations: A communication boundary management perspective. Communication Studies, 51, 116-134. doi: $10.1080 / 10510970009388513$

Chassin, L., \& Barrera, M. (1993). Substance use escalation and substance use restraint among adolescent children of alcoholics. Psychology of Addictive Behavior, 7, 320. doi:10.1037/0893-164X.7.1.3

Chassin, L., Rogosch, F., \& Barrera, M. (1991). Substance use and symptomatology among adolescent children of alcoholics. Journal of Abnormal Psychology, 100, 449-463. doi:10.1037/0021-843X.100.4.449 
Chermack, S. T., Stoltenberg, S. F., Fuller, B. E., \& Blow, F. C. (2000). Gender differences in the development of substance-related problems: The impact of family history of alcoholism, family history of violence, and childhood conduct problems. Journal of Studies on Alcohol, 61, 845-852.

Child, J. T., \& Pearson, J. C. (2009, November). Family privacy orientations, parental privacy invasions, and parental attachment security: Connecting cognitive approaches to young adults' communication privacy orientation. Paper presented at the meeting of the National Communication Association, Chicago, IL.

Christians, C. G. (2000). Ethics and politics in qualitative research. In N. K. Denzin \& Y. S. Lincoln (Eds.), Handbook of qualitative research (2nd ed., pp. 133-154). Thousand Oaks, CA: SAGE.

Clair, D., \& Genest, M. (1987). Variables associated with the adjustment of offspring of alcoholic fathers. Journal of Studies on Alcohol, 32, 687-698.

Clair, D. J., \& Genest, M. (1992). The children of alcoholics screening test: Reliability and relationship to family environment, adjustment, and alcohol-related stressors of adolescent offspring of alcoholics. Journal of Clinical Psychology, 48, 414420. doi:10.1002/1097-4679(199205)48:3<414::AIDJCLP2270480321>3.0.CO;2-N

Cline, R. J., \& McKenzie, N. J. (2000). Dilemmas of disclosure in the age of HIV/AIDS: Balancing privacy and protection in the health care context. In S. Petronio (Ed.), Balancing the secrets of private disclosures (pp. 165-180). Mahwah, NJ: Erlbaum. 
Cohen, S., \& Wills, T. A. (1985). Stress, social support, and the buffering hypothesis. Psychological Bulletin, 98, 310-357.

Cornwell, G. (1968). Factors in interpersonal and family relationships and alcoholism. Journal of Psychiatric Nursing \& Mental Health Services, 6, 274-278.

Cotton, N. S. (1979). The familial incidence of alcoholism: A review. Journal of Studies on Alcohol, 40, 89-116.

Coupland, N., Coupland, J., \& Giles, H. (1991). Language, society, and the elderly: Discourse, identity, and ageing. Oxford, England: Blackwell.

Crocker, J., \& Major, B. (1989). Social stigma and self-esteem: The self-protective properties of stigma. Psychological Review, 96, 608-630.

Curran, P. J., \& Chassin, L. (1996). A longitudinal study of parenting as a protective factor for children of alcoholics. Journal of Studies on Alcohol, 57, 305-314.

Currier, K. D., \& Aponte, J. J. (1991). Sexual dysfunction in female adult children of alcoholics. International Journal of Addictions, 26, 195-201.

Dawson, D. A., Brant, B. F., Chou, S. P., \& Stinson, F. S. (2007). The impact of partner alcohol problems on women's physical and mental health. Journal of Studies on Alcohol and Drugs, 68, 66-75.

Day, B. R. (1961). Alcoholism and the family. Marriage and Family Living, 23, 253-258. doi: $10.2307 / 346970$

Denzin, N. K., \& Lincoln, Y. S. (2000). The discipline and practice of qualitative research. In N. K. Denzin \& Y. S. Lincoln (Eds.), Handbook of qualitative research (2nd ed., pp. 1-28). Thousand Oaks: CA: SAGE. 
Derlega, V. J., \& Chaikin, A. L. (1977). Privacy and self-disclosure in social relationships. Journal of Social Issues, 33, 102-115.

Derlega, V. J., Winstead, B. A., Mathews A., \& Braitman, A. L. (2008). Why does someone reveal highly personal information?: Attributions for and against selfdisclosure in close relationships. Communication Research Reports, 25, 115-130. doi: $10.1080 / 08824090802021756$

Deutsch, C. (1982). Broken bottles, broken dreams: Understanding and helping the children of alcoholics. New York, NY: Teachers College Press.

Díaz, R., Gual, A., García, M., Arnau, J., Pascual, F., Cañuelo, B.,...Garbayo, I. (2008). Children of alcoholics in Spain: From risk to pathology. Social Psychiatry and Psychiatric Epidemiology, 43, 1-10. doi:10.1007/s00127-007-0264-2

Dinning, W. D., \& Berk, L. A. (1989). The children of alcoholics screening test: Relationship to sex, family environment, and social adjustment in adolescents. Journal of Clinical Psychology, 45, 335-339.

Domenico, D., \& Windle, M. (1993). Intrapersonal and interpersonal functioning among middle-aged female adult children of alcoholics. Journal of Consulting and Clinical Psychology, 61, 659-666. doi:10.1037/0022-006X.61.4.659

Drake, R. E., \& Vaillant, G. E. (1988). Predicting alcoholism and personality disorder in a 33-year longitudinal study of children of alcoholics. British Journal of Addiction, 83, 799-807. doi:10.1111/j.1360-0443.1988.tb00515.x

Duncan, A. E., Scherrer, J., Fu, Q., Bucholz, K. K., Heath, A. C., True, W. R.,...Jacob, T. 
(2006). Exposure to paternal alcoholism does not predict development of alcoholuse disorders in offspring: Evidence from an offspring-of-twins study. Journal of Studies on Alcohol, 67, 649-656.

Durham, W. T. (2008). The rules-based process of revealing/concealing the family planning decisions of voluntarily child-free couples: A communication privacy management perspective. Communication Studies, 59, 132-147. doi:

$10.1080 / 10510970802062451$.

Durham, W. T., \& Braithwaite, D. O. (2009). Communication privacy management within the family planning trajectories of voluntarily child-free couples. Journal of Family Communication, 9, 43-65. doi: 10.1080/15267430802561600

Eiden, R., D., Edwards, E. P., \& Leonard, K. E. (2004). Predictors of effortful control among children of alcoholic and nonalcoholic fathers. Journal of Studies on Alcohol, 65, 309-319.

El-Guebaly, N., Walker, J. R., Ross, C. A., \& Currie, R. F. (1990). Adult children of problem drinkers in an urban community. The British Journal of Psychiatry, 156, 249-255. doi:10.1192/bjp.156.2.249

El-Guebaly, N., West, M., Maticka-Tyndale, E., \& Pool, M. (1993). Attachment among adult children of alcoholics. Addiction, 88, 1405-1411. doi:10.1111/j.13600443.1993.tb02027.x

Epping, D., \& Hammonds, J. (2007, November). An examination of the communication and privacy rules of GLBT individuals with their parents. Paper presented at the meeting of the National Communication Association, Chicago, IL. 
Finlay, D. G. (1974). Alcoholism: Illness or problem in interaction? Social Work, 19, 398-405.

Fitzgerald, H. E., Puttler, L. I., Refior, S., \& Zucker, R. A. (2007). Family response to children and alcohol. Alcoholism Treatment Quarterly, 25, 11-25. doi:10.1300/J020v25n01_02

Fredricks, R. (1993, November). Communication apprehension among adult children of alcoholics. Paper presented at the meeting of the Speech Communication Association, Miami Beach, FL.

Frey, L. R., Botan, C. H., \& Kreps, G. L. (2000). Investigating communication: An introduction to research methods ( $2^{\text {nd }}$ ed.). Boston, MA: Allyn and Bacon.

Geddes, D. S. (1999). A spiritual tapestry: Descriptions of the recovery experience of adult children of alcoholics. In L. S. Eastland, S. L. Herndon, \& J. R. Barr (Eds.), Communication in recovery: Perspectives on twelve-step groups, (pp. 245262). Cresskill, NJ: Hampton Press.

Gibbs, J. L., Lai, C. H., \& Ellison, N. B. (2009, November). First comes loves, then comes Google: An investigation of communication privacy management strategies and self disclosure in online dating. Paper presented at the annual meeting of the National Communication Association, Chicago, IL.

Giglio, J. J., \& Kaufman, E. (1990). The relationship between child and adult psychopathology in children of alcoholics. The International Journal of the Addictions, 25, 263-290.

Glaser, B. G., \& Strauss, A. L. (1967). The discovery of grounded theory: Strategies for qualitative research. Chicago, IL: Aldine. 
Grant, B. F. (1998). The impact of a family history of alcoholism on the relationship between age at onset of alcohol use and DSM-IV alcohol dependence: Results from the National Longitudinal Alcohol Epidemiologic Survey. Alcohol Health \& Research World, 22, 144-147.

Grant, B. F. (2000). Estimates of US children exposed to alcohol abuse and dependence in the family. American Journal of Public Health, 90, 112-115.

Grant, C. H., Rosenfeld, L. B., \& Cissna, K. N. (2004). The effects of family-of-origin alcohol abuse on the self-perceived communication competence of the children. Communication Research Reports, 21, 47-59.

Gravitz, H. L. (1985). Children of alcoholics handbook. South Laguna, CA: The National Association for Children of Alcoholics.

Greenberg, M. A., \& Stone, A. A. (1992). Emotional disclosure about traumas and its relation to health: Effects of previous disclosure and trauma severity. Journal of Personality and Social Psychology, 63, 75-84. doi:10.1037/0022-3514.63.1.75

Grekin, E. R., Brennan, P. A., \& Hammen, C. (2005). Parental alcohol use disorders and child delinquency: The mediating effects of executive functioning and chronic family stress. Journal of Studies on Alcohol, 66, 14-22.

Groh, D. R., Jason, L. A., Davis, M. I., Olson, B. D., \& Ferrari, J. F. (2007). Friends, family, and alcohol abuse: An examination of general and alcohol-specific social support. The American Journal on Addictions, 16, 49-55.

doi:10.1080/10550490601080084 
Gudykunst, W. B. (1983). Uncertainty reduction and predictability of behavior in lowand high-context cultures: An exploratory study. Communication Quarterly, 31, 49-55. doi: 10.1080/01463378309369485

Haber, J. R., \& Jacob, T. (1997). Marital interactions of male versus female alcoholics. Family Processes, 36, 385-402. doi:10.1111/j.1545-5300.1997.00385.x

Hardwick, C. J., Hansen, N. D., \& Bairnsfather, L. (1995). Are adult children of alcoholics unique?: A study of object relations and reality testing. The International Journal of the Addictions, 30, 525-529.

Harrington, C. M., \& Metzler, A. E. (1997). Are adult children of dysfunctional families with alcoholism different from adult children or dysfunctional families without alcoholism? A look at committed, intimate relationships. Journal of Counseling Psychology, 44, 102-107. doi:10.1037/0022-0167.44.1.102

Haugland, B. S. M. (2005). Recurrent disruption of rituals and routines in families with paternal alcohol abuse. Family Relations, 54, 225-241. doi:10.1111/j.01976664.2005.00018.x

Hawkins, C. A. (1997). Disruption of family rituals as a mediator of the relationship between parental drinking and adult adjustment in offspring. Addictive Behaviors, 22, 219-231. doi:10.1016/S0306-4603(96)00011-1

Hecht, M. (1973). Children of alcoholics are children at risk. The American Journal of Nursing, 73, 1764-1767. doi:10.2307/3422939

Hinkin, C. H., \& Kahn, M. W. (1995). Psychological symptomatology in spouses and adult children of alcoholics: An examination of the hypothesized personality 
characteristics of codependency. The International Journal of Addictions, 30, 843-861.

Hollenbaugh, E. E., \& Egbert, N. (2009). A test of communication privacy management theory in cross-sex friendship. Ohio Communication Journal, 47, 113-136.

Hosek, A. M., \& Thompson, J. (2009). Communication privacy management and college instruction: Exploring the rules and boundaries that frame instructor private disclosures. Communication Education, 58, 327-349. doi:

$10.1080 / 03634520902777585$

How will al-anon help me? (n.d.). Al-anon/Alateen. Retrieved from http://www.al anon.alateen.org/english.html

Humphreys, K., Finney, J. W., \& Moos, R. H. (1994). Applying a stress and coping framework to research on mutual help organizations. Journal of Community Psychology, 22, 312-327. doi:10.1002/1520-6629(199410)22:4<312::AIDJCOP2290220404>3.0.CO;2-6

Humphreys, K., Mankowski, E. S., Moos, R. H., \& Finney, J. W. (1999). Do enhanced friendship networks and active coping mediate the effect of self-help groups on substance abuse? Annals of Behavioral Medicine, 21, 54-60. doi:10.1007/BF02895034

Humphreys, K., Mavis, B. E., \& Stoffelmayr, B. E. (1994). Are twelve step programs appropriate for disenfranchised groups? Evidence from a study of posttreatment mutual help involvement. Prevention in Human Services, 11, 165-179. 
Humphreys, K., \& Noke, J. M. (1997). The influence of posttreatment mutual help group participation on the friendship networks of substance abuse patients. American Journal of Community Psychology, 25, 1-16. doi:10.1023/A:1024613507082

Jackson, J. K. (1954). The adjustment of the family to the crisis of alcoholism. Quarterly Journal of Studies on Alcohol, 15, 562-586.

Jackson, J. K. (1956). The adjustment of the family to alcoholism. Marriage and Family Living, 18, 361-369. doi:10.2307/347283

Jackson, J. K. (1958). Alcoholism and the family. The Annals of The American Academy of Political and Social Science, 315, 90-98. doi:10.1177/000271625831500112

Jacob, T., \& Leonard, K. E. (1986). Psychosocial functioning in children of alcoholic fathers, depressed fathers, and control fathers. Journal of Studies on Alcohol, 47, 373-380.

Jacob, T., \& Windle, M. (2000). Young adult children of alcoholic, depressed, and nondistressed parents. Journal of Studies on Alcohol, 61, 836-844.

Jacob, T., Leonard, K. E. \& Haber, J. R. (2001). Family interactions of alcoholics as related to alcoholism and drinking condition. Alcoholism: Clinical and Experimental Research, 25, 835-843. doi:10.1111/j.1530-0277.2001.tb02287.x

Jahn, M. F. (1995). Family secrets and family environment: Their relation to later adult functioning. Alcoholism Treatment Quarterly, 13, 71-80. doi: 10.1300/J020V1N02_06

Jarmas, A. L., \& Kazak, A. E. (1992). Young adult children of alcoholic fathers: Depressive experiences, coping styles, and family systems. Journal of Consulting and Clinical Psychology, 60, 244-251. doi:10.1037/0022-006X.60.2.244 
Jellinek, E. M. (1952). Phases of alcohol addiction. Quarterly Journal of Studies of Alcohol, 13, 673-684.

Jellinek, E. M. (1960). The disease concept of alcoholism. New Haven, CT: Hillhouse Press.

Johnson, P. (2001). Dimensions of functioning in alcoholic and nonalcoholic families. Journal of Mental Health Counseling, 23, 127-136.

Johnson, P. (2002). Predictors of family functioning within alcoholic families. Contemporary Family Therapy, 21, 371-384. doi:10.1023/A:1015307626704

Johnson, J. L., \& Rolf, J. E. (1988). Cognitive functioning in children from alcoholic and non-alcoholic families. British Journal of Addiction, 83, 849-857. doi:10.1111/j.1360-0443.1988.tb00520.x

Johnson, J. L., \& Rolf, J. E. (1990). When children change: Research perspectives on children of alcoholics. In R. L. Collins, K. E. Leonard, \& J. S. Searles (Eds.), Alcohol and the family: Research and clinical perspectives (pp. 162-193). New York, NY: Guilford Press.

Jones, W. H., \& Houts, R. (1992). Parental drinking, parent-child communication, and social skills in young adults. Journal of Studies on Alcohol, 53, 48-56.

Karpel, M. A. (1980). Family secrets: I. Conceptual and ethical issues in the relational context, II. Ethical and practical considerations in therapeutic management. Family Process, 19, 295-306. doi:10.1111/j.1545-5300.1980.00295.x

Kashubeck, S., (1994). Adult children of alcoholics and psychological distress. Journal of Counseling and Development, 72, 538-543. 
Kashubeck, S. \& Christensen, S. A. (1992). Differences in distress among adult children of alcoholics. Journal of Counseling Psychology, 39, 356-362. doi:10.1037/00220167.39.3.356

Kaufman, E. (1986). The family of the alcoholic patient. Psychosomatics, 27, 347-360.

Kearns-Bodkin, J. N., \& Leonard, K. E. (2008). Relationship functioning among adult children of alcoholics. Journal of Studies on Alcohol, 69, 941-950.

Keller, M. (1958). Alcoholism: Nature and extent of the problem. Annals of the American Academy of Political and Social Science, 315, 1-11. doi: $10.1177 / 000271625831500102$

Kelley, M. L., French, A., Bountress, K., Keefe, H. A., Schroeder, V., Steer, K.,...Gumienny, L. (2007). Parentification and family responsibility in the family of origin of adult children of alcoholics. Addictive Behaviors, 32, 675-685. doi:10.1016/j.addbeh.2006.06.010

Kelly, A. E., Klusas, J. A., von Weiss, R. T., \& Kenny, C. (2001). What is it about revealing secrets that is beneficial? Personality and Social Psychology Bulletin, 27, 651-665. doi:10.1177/0146167201276002

Koesten, J. (2004). Family communication patterns, sex of subject, and communication competence. Communication Monographs, 71, 226-244. doi:

$10.1080 / 0363775032000104568$

Kubicka, L., Csémy, L., \& Kozený, J. (1992). A case-control study of risk factors of alcohol misuse in Czech women: Are there four types of female alcoholism? The International Journal of the Addictions, 27, 1105-1118. doi:10.3109/10826089209047337 
Kuhn, A. (2002). Family secrets: Acts of memory and imagination. New York, NY: New Left Books.

Lannutti, P. (2009, May). Tying the knot?: Couples' deliberations regarding legally recognized same-sex marriage. Paper presented at the meeting of International Communication Association, Chicago, IL.

Ledbetter, A. M., Heiss, S., Sibal, K., Lev, E., Battle-Fisher, M., \& Shubert, N. (2010). Parental invasive and children's defensive behaviors at home and away at college: Mediated communication and privacy boundary management. Communication Studies, 61, 184-204. doi: 10.1080/10510971003603960

Lev, E. (2008, November). “So what's bringing you in today?” Exploring privacy management within a small town express care clinic. Paper presented at the meeting of the National Communication Association, San Diego, CA.

Li, S., Van Lear, C. A., \& Rangarajan, S. (2007, May). Communication, social support, and emotional quality of life in alcoholism recovery. Paper presented at the meeting of the International Communication Association, San Francisco, CA.

Liberto, J. G., \& Oslin, D. W. (1995). Early versus late onset of alcoholism in the elderly. The International Journal of the Addictions, 30, 1799-1818. doi:10.3109/10826089509071056

Lieber, C. S. (Ed.). (1977). Metabolic aspects of alcoholism. Baltimore, MD: University Park Press.

Manzardo, A. M., Goodwin, D. W., Campbell, J. L., Penick, E. C., \& Gabrielli, Jr., W. F. (2008). The facts: Alcoholism (4th ed.). New York, NY: Oxford University Press. 
Martin, J. I. (1995). Intimacy, loneliness, and openness to feelings in adult children of alcoholics. Health \& Social Work, 20, 52-59.

Mathews, A., Derlega, V. J., \& Morrow, J. (2006). What is highly personal information and how is it related to self-disclosure decision making? The perspective of college students. Communication Research Reports, 23, 85-92. doi:

$10.1080 / 08824090600668915$

Mattson, M., \& Brann, M. (2002). Managed care and the paradox of patient confidentiality: A case study analysis from the a communication boundary management perspective. Communication Studies, 53, 337-357. doi: $10.1080 / 10510970209388597$

McBride, M. C., \& Braithwaite, D. O. (2008, May). Doing facework while managing private information: Talking with family members about romantic relationship problems. Paper presented at the meeting of the International Communication Association, Montreal, Canada.

McCord, W., \& McCord, J. (1960). Origins of alcoholism. Stanford, CA: Stanford University Press.

McMahon, R. C., Kouzekanai, K., DeMarco, L. A., Kusel, S. J., \& Davidson, R. S. (1992). Cognitive motivations for drinking among alcoholics: Factor structure and correlates. American Journal of Drug and Alcohol Abuse, 18, 477- 489. doi:10.3109/00952999209051043

Miller, A. E. (2009). Revealing and concealing postmarital dating information: Divorced coparents' privacy rule development and boundary coordination processes. 
Journal of Family Communication, 9, 135-149. doi:

$10.1080 / 15267430902773287$

Mohr, C. D., Averna, S., Kenny, D. A., \& Del Boca, F. K. (2002). “Getting by (or getting high) with a little help from my friends": An examination of adult alcoholics' friendships. Journal of Studies on Alcohol, 62, 637-645.

Moore, J. S. (1992). Conceptions of alcoholism. The International Journal of the Addictions, 27, 935-945.

Moos, R. H., Bromet, E., Tsu, V., \& Moos, B. (1979). Family characteristics and the outcome of treatment for alcoholism. Journal of Studies on Alcohol, 40, 78-88.

Morr Serewicz, M. C., Dickson, F. C., Morrison, J. H. T. A., \& Poole, L. L. (2007).

Family privacy orientation, relational maintenance, and family satisfaction in young adults' family relationships. The Journal of Family Communication, 7, 123-142.

Morr Serewicz, M. C., \& Petronio, S. (2006). Communication privacy management theory. In B. B. Whaley \& W. Samter (Eds.), Explaining communication: Contemporary theories and exemplars (pp. 257-274). Mahwah, NJ: Lawrence Erlbaum Associates.

Mothershead, P. K., Kivlighan, D. M., Jr., \& Wynkoop, T. F. (1998). Attachment, family dysfunction, parental alcoholism, and interpersonal distress in late adolescence: A structural model. Journal of Counseling Psychology, 45, 196-203. doi:10.1037/0022-0167.45.2.196 
Mylant, M., Ide, B., Cuevas, E., \& Meehan, M. (2002). Adolescent children of alcoholics: Vulnerable or resilient? Journal of the American Psychiatric Nurses Association, 8, 57-64. doi:10.1067/mpn.2002.125037

National Institute on Alcohol Abuse and Alcoholism. (1990). Alcohol and women. Retrieved from http://pubs.niaaa.nih.gov/publications/aa10.htm.

National Institute on Alcohol Abuse and Alcoholism. (2007). FAQs for the general public. Retrieved from http://www.niaaa.nih.gov/FAQs/General-English/

Newell, N. (1950). Alcoholism and the father-image. Quarterly Journal of Studies on Alcohol, 11, 92-96.

Niedermyer, A. (2008, November). Walking the high-wire: An examination of coownership and eventual betrayal of trust in individuals who share another friend's secrets with a third party. Paper presented at the meeting of the National Communication Association, San Diego, CA.

Olenick, N. L., \& Chalmers, D. K. (1991). Gender-specific drinking styles in alcoholics and nonalcoholics. Journal of Studies on Alcohol, 52, 325-330.

Ooteman, W., Koeter, M., Verheul, R., Schippers, G., \& Van den Brink, W. (2006). Development and validation of the Amsterdam motives for drinking scale (AMDS): An attempt to distinguish relief and reward drinkers. Alcohol \& Alcoholism, 41, 284-292. doi:10.1093/alcalc/ag1012

Opdenakker, R. (2006). Advantages and disadvantages of four interview techniques qualitative research. Retrieved from http://www.qualitativeresearch.net/index.php/fqs/article/viewArticle/175/391

Orford, J., Hawker, A., \& Nicholls, P. (1975). An investigation of an alcoholism 
rehabilitation halfway house: III. Reciprocal staff-resident evaluations. British Journal of Addiction, 70, 23-32. doi:10.1111/j.1360-0443.1975.tb00004.x

Owen, W. F. (1984). Interpretive themes in relational communication. Quarterly Journal of Speech, 70, 274-287. doi:10.1080/00335638409383697

Parsons, T. (2003). Alcoholism and its effect on the family. Retrieved from http://allpsych.com/journal/alcoholism.html.

Pennebaker, J. W., Kiecolt-Glaser, J. K., \& Glaser, R. (1988). Disclosure of traumas and immune function: Health implications for psychotherapy. Journal of Consulting and Clinical Psychology, 55, 1243-1254.

Pennebaker, J. W., Zech, E., \& Rimé, B. (2001). Disclosing and sharing emotion: Psychological, social, and health consequences. In M. S. Stroebe, W. Stroebe, R. O. Hansson, \& H. Schut (Eds.), Handbook of bereavement research: Consequences, coping, and care (pp. 517-539). Washington, D. C.: American Psychological Association.

Perrin, T. (1985). Inadequate, inconsistent...nonexistent parenting: A dilemma for children from alcoholic families. In M. Miller (Ed.), Changing legacies: Growing up in an alcoholic home (pp. 57-64). Pompano Beach, FL: Health Communications.

Petronio, S. (1991). Communication boundary management: A theoretical model of managing disclosure of private information between martial partners. Communication Theory, 1, 311-335. doi:10.1111/j.1468-2885.1991.tb00023.x Petronio, S. (2000). The boundaries of privacy: Praxis of everyday life. In S. Petronio 
(Ed.), Balancing the secrets of private disclosures (pp. 37-49). Mahwah, NJ: Erlbaum.

Petronio, S. (2002). Boundaries of privacy: Dialectics of disclosure. New York, NY: State University of New York Press.

Petronio, S., Flores, L., \& Hecht, M. (1997). Locating the voice of logic: Disclosure discourse of sexual abuse. Western Journal of Communication, 61, 101-113.

Petronio, S., \& Kovach, S. (1997). Managing privacy boundaries: Health providers' perceptions of resident care in Scottish nursing homes. Journal of Applied Communication Research 25, 115-131. doi:10.1080/00909889709365470

Petronio, S., Reeder, H. M., Hecht, M. L., \& Ros-Mendoza, T. M. (1996). Disclosure of sexual abuse by children and adolescents. Journal of Applied Communication Research, 24, 181-199. doi: 10.1080/00909889609365450

Petronio, S., \& Reierson, J. (2009). Regulating the privacy of confidentiality: Grasping the complexities through communication privacy management theory. In T. D. Afif \& W. A. Afifi (Eds.), Uncertainty, information management, and disclosure decisions: Theories and applications (pp. 365-383). New York, NY: Taylor \& Francis.

Petronio, S., Sargent, J., Andea, L., Reganis, P., \& Cichocki, D. (2004). Family and friends as informal healthcare advocates. Journal of Social and Personal Relationships, 21, 33-52. doi:10.1177/0265407504039838

Petry, N. M., Kirby, K. N., \& Kranzler, H. R. (2002). Effects of gender and family history of alcohol dependence on a behavioral task of impulsivity in healthy subjects. Journal of Studies on Alcohol, 63, 83-90. 
Piazza, N. J., Vrbka, J. L., \& Yeager, R. D. (1989). Telescoping of alcoholism in women alcoholics. The International Journal of the Addictions, 24, 19-28. doi: $10.3109 / 10826088909047272$

Polk, D., \& Hullman, G. (2008, November). Self-disclosure about weight: The role of stigma and the implications for women's health. Paper presented at the meeting of the National Communication Association, San Diego, CA.

Potter, A. E., \& Williams, D. E. (1991). Development of a measure examining children's roles in alcoholic families. Journal of Studies on Alcohol, 52, 70-77.

Preli, R., Protinksy, H., \& Cross, L. (1990). Alcoholism and family structure. Family Therapy, 27, 1-8.

Priest, K. (1985). Adolescents' response to parents' alcoholism. The Journal of Contemporary Social Work, 66, 533-539.

Protinsky, H., \& Ecker, S. (1990). Intergenerational family relationships as perceived by adult children of alcoholics. Family Therapy, 17, 217-222.

Rangarajan, S. (2006, May). Lonely in a crowd: The social and emotional consequences of growing up with parental alcoholism. Paper presented at the meeting of the International Communication Association, Dresden, Germany.

Rangarajan, S., \& Kelly, L. (2006). Family communication patterns, family environment, and the impact of parental alcoholism on offspring self-esteem. Journal of Social and Personal Relationships, 23, 655-671. doi: 10.1177/0265407506065990

Rankin, C., \& Bustle, J. (2008, November). Should relational history be discussed? An 
application and extension of communication privacy management. Paper presented at the meeting of the National Communication Association, San Diego, CA.

Rearden, J. J., \& Markwell, B. S. (1989). Self concept and drinking problems of college students raised in alcohol-abused homes. Addictive Behaviors, 14, 225-227. doi:10.1016/0306-4603(89)90053-1

Reich, W., Earls, F., \& Powell, J. (1988). A comparison of the home and social environments of children of alcoholic and non-alcoholic parents. British Journal of Addiction, 83, 831-839. doi:10.1111/j.1360-0443.1988.tb00518.x

Ritter, J., Stewart, M., Bernet, C., Coe, M., \& Brown, S. A. (2002). Effects of childhood exposure to familiar alcoholism and family violence on adolescent substance use, conduct problems, and self-esteem. Journal of Traumatic Stress, 15, 113-122.

Robinson, B. E., \& Rhoden, J. L. (1998). Working with children of alcoholics: A practitioner's handbook. Thousand Oaks, CA: SAGE.

Rolf, J. E., Johnson, J. L., Israel, E., Baldwin, J., \& Chandra, A. (1988). Depressive affect in school-aged children of alcoholics. British Journal of Addiction, 83, 841-848. doi:10.1111/j.1360-0443.1988.tb00519.x

Ross, L. T., \& McDuff, J. A. (2008). The retrospective family unpredictability scale: Reliability and validity. Journal of Child and Family Studies, 17, $13-27$. doi:10.1007/s10826-007-9138-1

Rubio-Stipec, M., Bird, H., Canino, G., Bravo, M., \& Alegria, M. (1991). Children of alcoholic parents in the community. Journal of Studies on Alcohol, 52, 78-88. 
Sabee, C. (2008, November). Secondary goals in boundary management: Choosing to bring in a third party mediator (or not). Paper presented at the meeting of the National Communication Association, San Diego, CA.

Schuckit, M. A., Tipp, J. E., \& Kelner, E. (1994). Are daughters of alcoholics more likely to marry alcoholics? American Journal of Drug and Alcohol Abuse, 20, 237-245. doi:10.3109/00952999409106784

Scott, W. A. (1955). Reliability of content analysis: The case of nominal scale coding. Public Opinion Quarterly, 19, 321-325. doi:10.1086/266577

Senchak, M., Greene, B. W., Carroll, A., \& Leonard, K. E. (1996). Global, behavioral and self ratings of interpersonal skills among adult children of alcoholic, divorced and control parents. Journal of Studies on Alcohol, 57, 638-645.

Shapiro Jr., D. H., Weatherford, V., Kaufman, E., \& Broenen, R. E. (1994). A control profile of adult children of alcoholics: A preliminary investigation. American Journal of Drug \& Alcohol Abuse, 20, 247-262. doi:10.3109/00952999409106785

Sher, K. J. (1997). Psychological characteristics of children of alcoholics. Alcohol Health \& Research World, 21, 247-254.

Sher, K. J., Walitzer, K. S., Wood, P. K., \& Brent, E. E. (1991). Characteristics of children of alcoholics: Putative risk factors, substance use and abuse, and psychopathology. Journal of Abnormal Psychology, 100, 427-448. doi:10.1037/0021-843X.100.4.427

Sheridan, M. J. (1995). A proposed intergenerational model of substance abuse, family functioning, and abuse/neglect. Child Abuse \& Neglect, 19, 519-530.

Sillars, A. (1995). Communication and family culture. In M. A. Fitzpatrick \& A. L. 
Vangelisti (Eds.), Explaining family interactions (pp. 375-399). Thousand Oaks, CA: SAGE.

Slutske, W. S., Heath, A. C., Madden, P. A. F., Bucholz, K. K., Dinwiddie, S. H., \& Dune, M. P. (1996). Reliability and reporting biases for perceived parental history of alcohol-related problems: Agreement between twins and differences between discordant pairs. Journal of Studies on Alcohol, 57, 387-395.

Spinatsch, M. (1992). The prediction of long-term outcome of male alcoholics after inpatient treatment: The case of a clinical population in German-speaking Switzerland. The International Journal of the Addictions, 27, 1087-1103.

Steinglass, P. (1971). Experimenting with family treatment approaches to alcoholism, 1950-1975: A review. Family Process, 15, 97-123. doi:10.1111/j.15455300.1976.00097.x

Steinglass, P. (1980). A life history model of the alcoholic family. Family Process, 19, 211-226. doi:10.1111/j.1545-5300.1980.00211.x

Steinglass, P. (1981). The impact of alcoholism on the family: Relationship between degree of alcoholism and psychiatric symptomatology. Journal of Studies on Alcohol, 42, 288-303.

Steinglass, P. (1987). The alcoholic family. New York, NY: Basic Books.

Steinglass, P., \& Moyer, J. K. (1977). Assessing alcohol use in family life: A necessary but neglected area for clinical research. The Family Coordinator, 26, 53-60. doi:10.2307/581861

Steinglass, P., Weiner, S., \& Mendelson, J. (1971). A systems approach to alcoholism: A model and its clinical application. Archives of General Psychiatry, 24, 401-408. 
Stigma associated with alcohol dependence treatment. (2009). Alcohol answers: Evidence based treatment \& support. Retrieved from http://www.alcoholanswers.org/alcohol-education/stigma-alcohol-dependencetreatment.cfm.

Stout, M. L., \& Mintz, L. B. (1996). Differences among nonclinical college women with alcoholic mothers, alcoholic gathers, and nonalcoholic parents. Journal of Counseling Psychology, 43, 466-472. doi:10.1037/0022-0167.43.4.466

Stow, C. A. H. (2009, November). An examination of college students' conflict with their families and privacy boundaries during the launching phase. Paper presented at the meeting of the National Communication Association, Chicago, IL.

Tamerin, J. S., Tolor, A., \& Harrington, B. (1976). Sex differences in alcoholics: A comparison of male and female alcoholics' self and spousal perceptions. The American Journal of Drug and Alcohol Abuse, 3, 457-472. doi:10.3109/00952997609014287

Templer, D. I. (1974). Essential alcoholism and family history of alcoholism. Quarterly Journal of Studies on Alcohol, 35, 655-657.

Terry, D. J., Rawle, R., \& Callan V. J. (1995). The effects of social support on adjustment to stress: The mediating role of coping. Personal Relationships, 2, 97-124. doi:10.1111/j.1475-6811.1995.tb00080.x

Thorson, A. R. (2009). Adult children's experiences with their parents infidelity: Communicative protection and access rules in the absence of divorce. Communication Studies, 60, 32-48. doi: 10.1080/10510970802623591 
Todd, J. E. (1882). Drunkenness a vice, not a disease. Hartford, CT: Case, Lockwood \& Brainard Company.

Tomori, M. (1994). Personality characteristics of adolescents with alcoholic parents. Adolescence, 29, 949-960.

Tweed, S. H., \& Ryff, C. D. (1991). Adult children of alcoholics: Profiles of wellness amidst distress. Journal of Studies on Alcohol, 52, 133-139.

Tyma, A.W. (2007). Rules of interchange: Privacy in online social communities--A rhetorical critique of MySpace.Com. Journal of the Communication, Speech \& Theatre Association of North Dakota, 20, 31-39.

Vangelisti, A. L. (1994). Family secrets: Forms, functions, and correlates. Journal of Social and Personal Relationships, 11, 113-135. doi:10.1177/0265407594111007

Vangelisti, A. L., Caughlin, J. P., \& Timmerman, L. (2001). Criteria for revealing family secrets. Communication Monographs, 68, 1-27. doi: 10.1080/03637750128052

Van Lear, C. A. (2006). A life of sobriety: Communication and taking steps on a pathway toward emotional quality of life. In R. M. Dailey \& B. A. LePoire (Eds.), Applied interpersonal communication matters (pp. 119-149). New York, NY: Peter Lang Publishing.

Van Lear, C. A., Brown, M. \& Anderson, E. (2003, May). Communication, social support, and emotional quality of life in the twelve-step sobriety maintenance process: Three studies. Paper presented at the meeting of the International Communication Association, San Diego, CA. 
Verheul, R., Van den Brink, W., \& Geerlings, P. (1999). A three-pathway

psychobiological model of craving for alcohol. Alcohol and Alcoholism, 34, 197222. doi:10.1093/alcalc/34.2.197

Walker, J. P., \& Lee, R. E. (1998). Uncovering strengths of children of alcoholic parents. Contemporary Family Therapy, 20, 521-538. doi:10.1023/A:1021684317493

Weber, K. M., \& Solomon, D. H. (2008). Locating relationship and communication issues among stressors associated with breast cancer. Health Communication, 23, 548-559. doi: 10.1080/10410230802465233

Wegscheider, S. (1981). Another chance: Hope \& health for the alcoholic family. Palo Alto, CA: Science and Behaviors Books.

Weiner, S., Tamerin, J. S., Steinglass, P., \& Mendelson, J. H. (1971). Familial patterns in chronic alcoholism: A study of a father and son during experimental intoxication. The American Journal of Psychiatry, 127, 1646-1651.

Weitzman, E. R., \& Wechsler, H. (2000). Alcohol use, abuse, and related problems among children of problem drinkers: Findings from a national survey of college alcohol use. The Journal of Nervous and Mental Disease, 188, 148-154. doi:10.1097/00005053-200003000-00004

Werner, E. E. (1986). Resilient offspring of alcoholics: A longitudinal study from birth to age 18. Journal of Studies on Alcohol, 47, 34-40.

Werner, E. E., \& Johnson, J. L. (2004). The role of caring adults in the lives of children of alcoholics. Substance Use \& Misuse, 39, 699-720. doi:10.1081/JA-120034012 
Werner, L. J., \& Broida, J. P. (1991). Adult self-esteem and locus of control as a function of familial alcoholics and dysfunction. Journal of Studies on Alcohol, 52, 249252.

Western, K. (2008, November). “Spilling the beans”: Exploring privacy management boundaries of families who adopt interracial and international children. Paper presented at the meeting of the National Communication Association, San Diego, CA.

Westin, A. (1967). Privacy and freedom. New York, NY: Atheneum Press.

Whipple, S. C., \& Noble, E. P. (1991). Personality characteristics of alcoholic fathers and their sons. Journal of Studies on Alcohol, 52, 331-337.

Williams, O. B., \& Corrigan, P.W. (1992). The differential effects of parental alcoholism and mental illness on their adult children. Journal of Clinical Psychology, 48, 406-414. doi:10.1002/1097-4679(199205)48:3<406::AIDJCLP2270480320>3.0.CO;2-L

Wilsnack, S. C., Klassen, A. D., Schur, B. E., \& Wilsnack, R. W. (1991). Predicting onset and chronicity of women's problem drinking: A five-year longitudinal analysis. American Journal of Public Health, 81, 305-318. doi:10.2105/AJPH.81.3.305

Wilsnack, R. W., Wilsnack, S. C., \& Klassen, A. D. (1981). Women’s drinking and drinking problems: Patterns from a 1981 national survey. American Journal of Public Health, 74, 1231-1238. doi:10.2105/AJPH.74.11.1231

Wilson, C. (1982). The impact on children. In J. Orford \& J. Harwin (Eds.), Alcohol and the family (pp. 151-166). Sydney, Australia: St. Martin's Press. 
Windle, M. (1997). Concepts and issues in COA research. Alcohol Health \& Research World, 21, 185-191.

Winokur, G., \& Clayton, P. J. (1968). Family history studies IV.: Comparison of male and female alcoholics. Quarterly Journal of Studies on Alcohol, 29, 885-891.

Woititz, J. G. (1983). Adult children of alcoholics. Pompano Beach, FL: Health Communications.

Woititz, J. G. (1986). Common characteristics of adult children from alcoholic families. In R. J. Ackerman (Ed)., Growing in the shadow: Children of alcoholics (pp. 175185). Pompano Beach, FL: Health Communications.

Wolin,S. J., Bennett, L. A., \& Jacobs, J. S. (1988). Assessing family rituals in alcoholic families. In E. Imber-Black, J. Roberts, \& R. A. Whiting (Eds.), Rituals in families and family theory (pp. 253-279). New York, NY: W. W. Norton \& Company, Inc.

Yalisove, D. (2004). Introduction to alcohol research: Implications for treatment, prevention, and policy. Boston, MA: Pearson.

Yeatman, F. R., Bogart, C. J., Geer, F. A., \& Sirridge, S. T. (1994). Children of alcoholics screening test: Internal consistency, factor structure, and relationship to measures of family environment. Journal of Clinical Psychology, 50, 931-936. doi:10.1002/1097-4679(199411)50:6<931::AID-JCLP2270500618>3.0.CO;2-M 


\section{Appendix A}

Handout Given at Al-Anon Meeting

\section{RATIONALE:}

Children of alcoholics are considered the population most affected by living with an alcoholic. They learn unstable, highly inconsistent behaviors, guess at what "normal" is, and have a more distorted perception of reality. Estimates indicate that the population of children of alcoholics is quite high. In the late 1990s, an estimated 28 million children in the United States were children of alcoholics. The alcoholic family often keeps a secret; they do not often share or acknowledge the drinking problem wi those outside the family. Living in this environment can contribute to children of alcoholics becoming less socially competent, less agreeable, less conscientious, and less open to experiences. However, it is often by sharing experiences and forming relationships with others that they are able to overcome thes negative experiences.

\section{PURPOSE:}

We are seeking adult children of male alcoholics to participate in interviews. The purpose of the interview is to examine children's perceptions of communication between family members and with those outside the family about alcoholism.

\section{BENEFITS TO YOU:}

Participating in an interview will enhance your understanding of how you and those around you discl your father's addiction. Additionally, by sharing your experiences, you will heighten others' awarene of the unique experiences adult children of alcoholics face.

\section{ELIGIBILITY REQUIREMENTS:}

To participate, you must be:

$>18$ years of age or older

$>$ Self identify as an adult child of an alcoholic

$>$ Have an alcoholic father

$>$ Have lived with alcoholic father while he was abusing alcohol

Your actual participation in the interview or your refusal to participate or withdrawal from this interview will in no way affect your job status.

If you want more information or are interested participating in an interview, please contact Kerry Byrnes using the contact information provided below.

Kerry Byrnes

$\mathrm{PhD}$ Candidate, Department of Communication Studies

West Virginia University

Phone: (304) 293-3905 


\section{Appendix B}

\section{Facebook Status}

Kerry Byrnes needs your help. If you are a child of a male alcoholic who does not mind sharing experiences you had while growing up in an alcoholic home, please, contact me to participate in a research study. 


\section{Appendix C}

\section{Logistics Information for Interviewees}

\begin{tabular}{|c|c|c|c|c|}
\hline Pseudonym & Age & Sex & Relationship & Location \\
\hline Brian & 22 & M & Father & Morgantown, West Virginia \\
\hline Elizabeth & 30 & $\mathrm{~F}$ & Father & Clarksburg, West Virginia \\
\hline Christy & 24 & $\mathrm{~F}$ & Father & New York, New York \\
\hline Diana & 32 & $\mathrm{~F}$ & Father & Austin, Texas \\
\hline Nancy & 30 & $\mathrm{~F}$ & Father & Muncie, Indiana \\
\hline Daniel & 22 & $\mathrm{M}$ & Father & Muncie, Indiana \\
\hline Nora & 24 & $\mathrm{~F}$ & Stepfather & Morgantown, West Virginia \\
\hline Jessica & 25 & $\mathrm{~F}$ & Father & Carmel, Indiana \\
\hline John & 32 & $\mathrm{M}$ & Stepfather & Indianapolis, Indiana \\
\hline Lucy & 20 & $\mathrm{~F}$ & Father & New York, New York \\
\hline Martha & 19 & $\mathrm{~F}$ & Father & Chicago, Illinois \\
\hline Jennifer & 34 & $\mathrm{~F}$ & Stepfather & Indianapolis, Indiana \\
\hline Polly & 28 & $\mathrm{~F}$ & Father & Nashua, New Hampshire \\
\hline Alexis & 35 & $\mathrm{~F}$ & Father & Chicago, Illinois \\
\hline Kim & 25 & $\mathrm{~F}$ & Father & Cincinnati, Ohio \\
\hline Janie & 22 & $\mathrm{~F}$ & Father & Morgantown, West Virginia \\
\hline Lindsey & 22 & $\mathrm{~F}$ & Father & Morgantown, West Virginia \\
\hline Abby & 28 & $\mathrm{~F}$ & Father & Round Rock, Texas \\
\hline Josh & 28 & M & Stepfather & Pinson, Alabama \\
\hline Kristy & 24 & $\mathrm{~F}$ & Father & Indianapolis, Indiana \\
\hline
\end{tabular}




\section{Appendix D}

Interview Guide

I'm Kerry Byrnes, a graduate student in the communication studies department. I am working on a project concerning children of alcoholics' communication about their parent's addiction. I am focused on those families that have an alcoholic father. Throughout our discussion, I'd like to request that you please do not include any names or other identifying information about the people you tell me about. I am interested in your perceptions of the communication that occurs within your family and with those outside your family. I will be tape recording our discussion. I want to give you this letter stating my research intentions, contact information, and IRB approval number.

1. Was or is your father an alcoholic? (yes) or (no) If yes,

2. How do you know that your father is an alcoholic?

3. What types of things does your family unit talk about?

4. How did you learn what you could talk about in the family?

5. How does having an alcoholic father make you feel?

6. How would you describe your father's drinking behaviors?

7. How long has your father been an alcoholic?

8. How long did you live at home with your alcoholic father?

9. What was your father's marital status while you lived at home?

10. When did you learn of your father's alcoholism?

a. How did you learn of it?

11. How do you decide what you will tell others about your alcoholic father?

a. What impacts your decision to tell others about your alcoholic father? 
b. What types of issues do you consider before telling someone of your father's alcoholism?

c. How does your sex, motivation, culture, context, risk-benefit, or past experiences influence your decision to tell people about your alcoholic father?

12. How did you learn about what you could talk about regarding your father's alcoholism with others?

a. How was the privacy rule acquired? (e.g., socialization, negotiation)

b. Who taught you how to talk to others?

13. Who knows about your father's alcoholism?

a. Within family? / Outside the family?

b. How did they learn about your father's alcoholism?

i. Did you tell them? Another way?

14. In what types of situations do you tell others about your father's alcoholism?

a. How willing are you to share information about your father's alcoholism with others?

15. How much information do you share with family members?

16. What types of information do you tell your family members?

17. How much information do you share with family outsiders?

18. What types of information do you tell family outsiders?

19. Do you talk about the same kinds of information related to your father's alcoholism with everyone? 
a. Do you and your family have routines about what can be talked about? (routinized)

b. Have you experienced situations that made you want to share information with others? (triggered event)

i. What did these situations look like?

c. Have you ever shared information with others that you knew your family would not want to be shared?

i. How did your family respond? (sanctions)

20. How is the information shared about your father's alcoholism similar or different with different people?

21. Why do you tell people about your father's alcoholism?

a. What influences you to share information? (e.g., strength/weakness of ties, how much information is shared, with whom information is shared)

i. type of information? / amount of information?

22. Do you ask those you tell about your father's alcoholism to keep the information secret or private? Why?

23. How do you and the people you tell about your father's alcoholism decide what can be done with the information?

24. Has anyone ever forced or otherwise pressured you to talk about your father? (inclusive boundary coordination)

i. Who was it?

ii. What was the situation surrounding this forced disclosure? 
25. While you are telling others about your father, do they ever disclose similar experiences? (intersected boundary coordination)

26. Does everyone in your family know about your father's alcoholism? (unified boundary coordination)

27. Has anyone you've told about your father ever told others about your father's alcoholism when you asked them not to?

28. Have you ever experienced any conflict about the information you have shared with others regarding your father's alcoholism?
a. What happened?
b. Why was there a problem?
c. Who was the problem with?

29. Do you feel that the person mishandled the information you shared intentionally or by accident?

a. Why do you think they misused the information? (e.g., intentional rule violation, boundary rule mistake, fuzzy boundaries, dissimilar boundary orientation, boundary definition predicament, privacy dilemma)

30. I'm really interested in learning more about the communication surrounding a father's alcoholism, is there anything else you would like to share? 


\section{Appendix E}

Code Book

\section{Management Process 1: Rule Foundations}

RQ1: What criteria do COAs use to develop privacy rules?

1. Tell others if prompted/talking about related topic

2. Emotional closeness

RQ2: What are the attributes of the privacy rules used to guide the disclosure of a father's alcoholism?

1. Socialized by nonalcoholic parent

2. Trigger: possible connection with others

\section{Management Process 2: Boundary Coordination Operations}

RQ3: With regard to information about a father's alcoholism, what are the boundaries that COAs create?

1. Who knows:

A. Immediate family (mom, siblings, step siblings)

B. Extended family (grandparents, aunts/uncles, cousins)

C. Non-familial relationships (churches, neighbors, friends)

2. What they know:

A. Amount of knowledge differs based on relationship (closer, more knowledge)

B. Amount of knowledge differs based on age (younger generation talks more)

RQ4: With regard to information about a father's alcoholism, how do COAs establish these boundaries?

1. Sharing:

A. Specific stories are often repeated (tend to be dramatic/memorable)

2. Willing to tell:

B. People emotionally close

C. Those with similar situations/identify to experiences

RQ5: With regard to information about a father's alcoholism, how do COAs manage these boundaries?

1. Don't ask people to keep private/secret

\section{Management Process 3: Boundary Turbulence}

RQ6: What types of boundary turbulence do COAs experience?

1. No conflict

\footnotetext{
${ }^{1}$ All names have been changed to pseudonyms.
} 